\title{
A gridded data set of upper-ocean hydrographic properties in the Weddell Gyre obtained by objective mapping of Argo float measurements
}

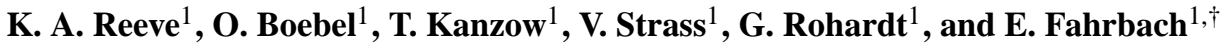 \\ ${ }^{1}$ Alfred-Wegener-Institut Helmholtz-Zentrum für Polar- und Meeresforschung, Bremerhaven, Germany \\ $\dagger$ deceased \\ Correspondence to: K. A. Reeve (kreeve@awi.de)
}

\begin{abstract}
Received: 3 March 2015 - Published in Earth Syst. Sci. Data Discuss.: 23 June 2015
Revised: 31 December 2015 - Accepted: 6 January 2016 - Published: 1 February 2016
\end{abstract}

\begin{abstract}
The Weddell Gyre plays a crucial role in the modification of climate by advecting heat poleward to the Antarctic ice shelves and by regulating the density of water masses that feed the lowest limb of the global ocean overturning circulation. However, our understanding of Weddell Gyre water mass properties is limited to regions of data availability, primarily along the Prime Meridian. The aim of this paper is to provide a data set of the upper water column properties of the entire Weddell Gyre. Objective mapping was applied to Argo float data in order to produce spatially gridded, time-composite maps of temperature and salinity for fixed pressure levels ranging from 50 to $2000 \mathrm{dbar}$, as well as temperature, salinity and pressure at the level of the sub-surface temperature maximum. While the data are currently too limited to incorporate time into the gridded structure, the data are extensive enough to produce maps of the entire region across three time-composite periods (2001-2005, 2006-2009 and 2010-2013), which can be used to determine how representative conclusions drawn from data collected along general RV transect lines are on a gyre scale perspective. The work presented here represents the technical prerequisite for addressing climatological research questions in forthcoming studies. The data sets are available in netCDF format at doi:10.1594/PANGAEA.842876.
\end{abstract}

\section{Introduction}

The Weddell Gyre provides an important link between the upper ocean and the ocean interior through the formation of Weddell Sea Deep Water (WSDW) and Weddell Sea Bottom Water (WSBW). WSDW in particular contributes significantly to Antarctic Bottom Water; a prominent water mass present throughout much of the abyssal global ocean (Orsi et al., 1999; Johnson, 2008). As such, the Weddell Gyre potentially plays a key role in a changing climate through its role in regulating the storage of heat in the deep ocean (Fahrbach et al., 2011). The main source water (and the main heat source) of the Weddell Gyre, Circumpolar Deep Water (CDW), enters at intermediate depths primarily from the east, although the open northern boundary permits intrusions of CDW to a lesser extent (Fahrbach et al., 2004; Klatt et al., 2005; Fahrbach et al., 2011; Cisewski et al., 2011). Upon entering the gyre, CDW becomes known as Warm Deep Water (WDW) and can be identified by its sub-surface potential temperature maximum of $0.6-1{ }^{\circ} \mathrm{C}$ (Fahrbach et al., 2011). WDW undergoes water mass transformation to form the underlying water masses. This process is controlled by (1) the transport and mixing of source waters into the gyre (Leach et al., 2011); (2) changes within the Weddell Gyre and on the adjacent shelves through influences from sea ice and ice shelves; and finally (3) the transport of modified water masses with the gyre outflow (Foster et al., 1987; Fahrbach et al., 1994, 1995, 2011). A schematic showing the basic Weddell Gyre circulation overlying a map of the bathymetry is shown in Fig. 1.

To date, the literature focusing on Weddell Gyre hydrography has been largely based on observations from repeat hydrographic sections - primarily collected during various cruises (see, e.g., Fahrbach et al., 2004, 2007, 2011), 


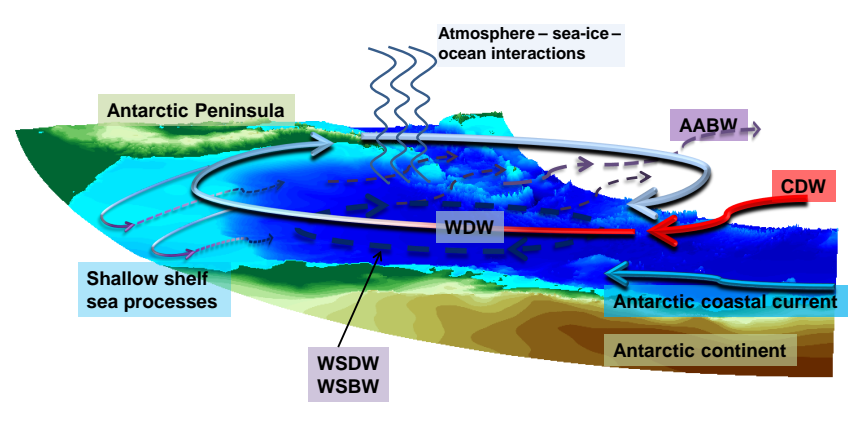

Figure 1. Schematic of Weddell Gyre circulation. The underlying 3-D map shows ocean bottom depth (IOC, IHO and BODC, 2003). Relatively warm Circumpolar Deep Water (CDW) enters from the east, becoming Warm Deep Water (WDW) which circulates in a cyclonic direction throughout the gyre, cooling en route, due to mixing with surrounding waters and interaction with the atmosphere and sea-ice processes. Shallow-shelf sea processes leads to the formation of cold, high-salinity water which, upon leaving the shelf, sinks below WDW to form Weddell Sea Deep and Bottom waters (WSDW \& WSBW); WSDW exits the gyre to the north to become Antarctic Bottom Water (AABW).

as well as data from moorings, deployed along both the Prime Meridian and strategically placed locations throughout the gyre (Klatt et al., 2005; Fahrbach and De Baar, 2010; Behrendt et al., 2011).These data are well-established (there are now 30 years of data collected from RV Polarstern alone). Historical measurements, however, date back to the early 1900s; for example, Brennecke (1918) combined the observations from Swedish (1901-1903), Scottish (19021904), French (1908-1910) and German (1911-1912) expeditions and provided sufficient evidence for proposing the cyclonic circulation of the Weddell Gyre. A review of historical research on the Weddell Gyre is provided by Deacon (1979). These data have provided us with a picture of the structure of the Weddell Gyre and have provided insight into the role of the Weddell Gyre from a larger climate perspective; Fahrbach et al. (2011) provides an in-depth comprehensive analysis of the variations within the Weddell System. However, much of the analysis of long-term changes is based on data along the Prime Meridian only - a region of high variability due to its close proximity to Maud Rise - influencing the relatively high-frequency fluctuations of observed WDW properties.

In addition to repeat hydrographic sections and moorings throughout the Weddell Gyre, there are also data from Argo floats, drifters and animal-borne sensors. These all combine to provide a multi-platform approach to observing the Weddell Gyre. Here, the authors focus on the Argo float data set, in order to provide an independent data set that can be compared to ship-based observations in the near future. Moorings are excluded from the analysis as they provide vertically sparse data, while drifters only provide surface data, which is excluded from the analysis due to high surface variabil- ity, and animal-borne sensors require special treatment due to salinity and depth sensor issues. Thus, delayed-mode adjusted Argo float data are the sole focus of this study.

The aim of this paper is to provide a spatially gridded data set of the upper water column properties with a particular focus on the entire Weddell Gyre. We describe the method followed in order to objectively map the irregular Argo float profile data onto regularly gridded fields (on both pressure surfaces and onto the level of the sub-surface temperature maximum), excluding regions beyond the Weddell Gyre boundaries (50 to $80^{\circ} \mathrm{S} ; 70^{\circ} \mathrm{W}$ to $40^{\circ} \mathrm{E}$; however, the northern boundary is based on the position of the Weddell Front for the pressure surface maps: Sect. 3.1). Associated mapping errors are also provided. While spatially gridded, the resulting mapped fields represent time composites of three separate time periods (2001-2005, 2006-2009 and 2010-2013), since the data are currently too limited to incorporate both a spatial and temporal averaging scheme.

\section{Source data description: Argo float profiles}

Argo is a global array of over 3500 free-drifting profiling floats that measure the temperature and salinity of the upper $2000 \mathrm{~m}$ of the ocean, allowing for continuous monitoring of the global upper ocean. While in the major ocean basins the data are abundant enough to provide a relatively uniform distribution throughout, the deployment of Argo floats at high latitudes has been considerably more limited; this was especially the case prior to 2007 . This is due to the risk of damage to floats resulting from the seasonal presence of sea ice, which prevents the float from surfacing or converges around the float while it is at the surface transmitting data to satellite, thus crushing and damaging the float. A sea-ice-sensing algorithm was introduced to floats after 2007 (Klatt et al., 2007), whereby floats "sense" the likelihood of sea ice at the surface and can abort attempts to surface, storing the hydrographic data until the next opportunity to surface arises. There are now over 10 years of Argo float data available for the entire Weddell Gyre region, from December 2001 to present, which can be used to determine the spatial variation of upper water column properties throughout the gyre.

Float profile data was retrieved from the Coriolis website (www.coriolis.eu.org). All profiles from within the Weddell Gyre region (50 to $80^{\circ} \mathrm{S} ; 70^{\circ} \mathrm{W}$ to $40^{\circ} \mathrm{E}$ ) from December 2001 to March 2013 were selected. While there are 25848 profiles, only profiles that have been subjected to delayed-mode quality control processing are used in this study, which leaves about 19600 . The profiles are checked for duplicates, which are subsequently removed (there were only three duplicate profiles from two floats overall). The profile distribution of the remaining profiles are shown in Fig. $2 \mathrm{~b}-\mathrm{d}$. The majority of available delayed-mode profiles occurs in 2008 and 2009 (Fig. 3). There is a clear seasonal bias in the number of profiles in the first half of the time 

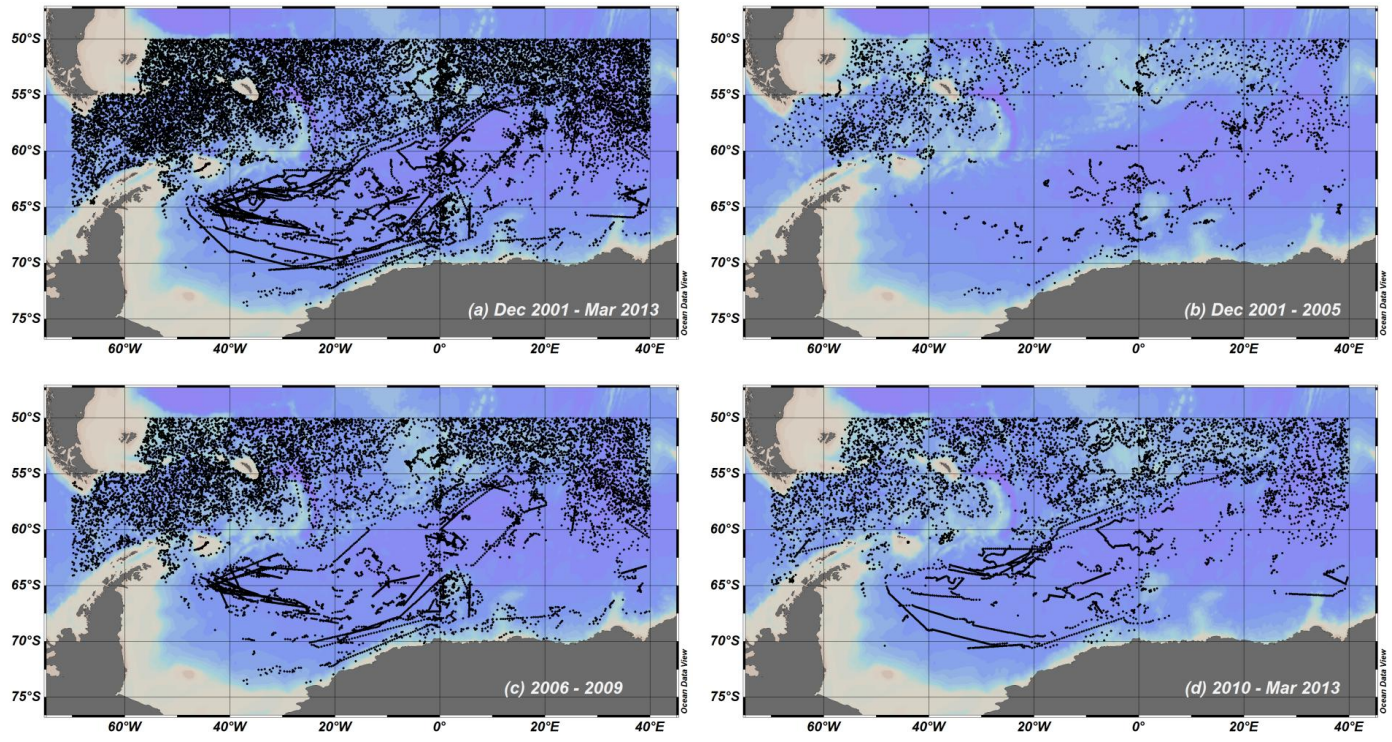

Figure 2. Argo float profile locations for (a) the entire time period, (b) time period (TP) 1, (c) TP2 and (d) TP3.
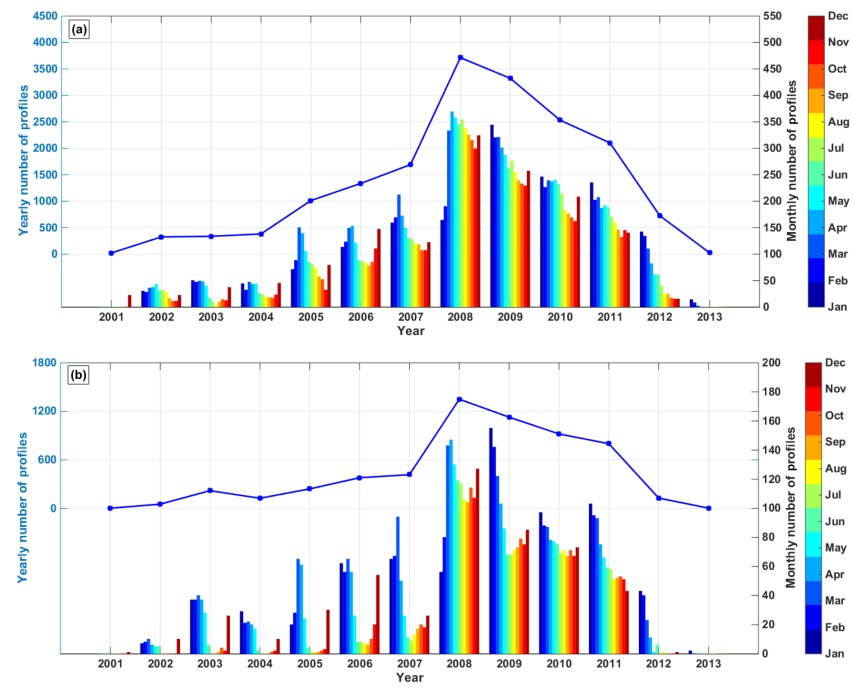

Figure 3. The number of profiles per year (line) and per month (bars) from (a) south of $50^{\circ} \mathrm{S}$ to the Antarctic continent and (b) south of $60^{\circ} \mathrm{S}$ to the Antarctic continent, between $70^{\circ} \mathrm{W}$ and $40^{\circ} \mathrm{E}$.

series, which reduces after 2007 due to improved float technology as mentioned above (Fig. 3). The majority of profiles have a vertical limit of $2000 \mathrm{dbar}$, although there are more than 1500 profiles that are limited to $1000 \mathrm{dbar}$ (about $75 \%$ of these profiles are actually located north of the Weddell Front, a frontal system which defines the northern boundary when mapping to pressure surfaces; see Sect. 3.1). These "shallow" float profiles most likely occur due to complex bottom bathymetry. Data are filtered according to their corresponding quality flags; only those with a quality flag of
1 are used, which indicates that the data have passed all quality control tests and that the "adjusted value is statistically consistent" (Wong et al., 2014; for more information about the quality control procedure of Argo floats, refer to the quality control manual at www.argodatamgt.org). Additionally, any data points for which the corresponding adjusted pressure error exceeds $20 \mathrm{dbar}$ are rejected. This is an extra precaution against pressure biases and is in accordance with the guidelines provided on the Argo website (www.argo.ucsd.edu). The temperatures in Argo are reported to be accurate to $\pm 0.002{ }^{\circ} \mathrm{C}$, while pressures are accurate to $\pm 2.4 \mathrm{dbar}$ (Owens and Wong, 2009). For salinity, if there is a small sensor drift; uncorrected salinities are accurate to $\pm 0.1 \mathrm{PSU}$, although this value can increase with increasing sensor drift. Delayed-mode processing subjects all float profiles to detailed scrutiny by comparison with historical data (Owens and Wong, 2009), providing corrected adjusted values while assigning each value with a quality flag. In the delayed-mode adjusted salinity data (with a quality flag of 1 ) used in this study, the mean adjusted salinity error is 0.01 , while the largest error does not exceed 0.1 .

Complications regarding position errors arise when the float enters the sea-ice zone. As already mentioned, new technology has allowed the floats to avoid surfacing in these regions. However, when a float profiles the water column under sea ice, it is not possible for the satellite to determine the float position. Thus, the position of an under-ice float profile is determined by linear interpolation between the last known profile position and the position of the first profile upon exiting the sea-ice zone, using the knowledge that floats perform on a 10-day cycle. Such profiles can be seen in particular in Fig. 4, where profiles with an interpolated location are marked in red. This situation will be improved as soon as 


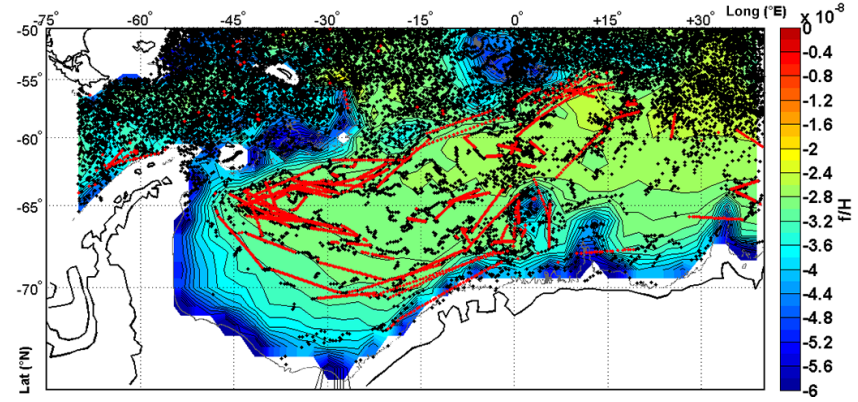

Figure 4. Argo float profile stations, with interpolated (under-ice) station locations are marked in red. The filled contours show lines of constant planetary potential vorticity, $f / H$. The grey contour shows the $2000 \mathrm{~m}$ isobath.

RAFOS data (Klatt et al., 2007) collected by some of these floats have been analysed. RAFOS floats are fitted with signal receivers and so have the potential to triangulate their positions based on the arrival times of sound signals from moorings deployed in the region. About $13 \%$ of all profiles south of $50^{\circ} \mathrm{S}$ have an interpolated location (about 2600 profiles), although this increases to about $38 \%$ south of $60^{\circ} \mathrm{S}$ (about 2340 profiles). The mean distance between under-ice profiles and their nearest neighbour is about $27 \mathrm{~km}$, although the largest distance is about $265 \mathrm{~km}$. The mean number of days between under-ice profiles and their nearest neighbour is about 24, while the range of days is between 7 and 270 . The influence of this uncertainty on the objective mapping will be discussed in Sect. 4 when assessing the robustness of the results.

Conservative temperature, absolute salinity and potential density are determined from the in situ temperature, practical salinity and pressure variables in the profile data, in accordance with TEOS-10 (the international thermodynamic equation of seawater - 2010; IOC et al., 2010). Conservative temperature is more representative of the "heat content" of seawater than potential temperature (McDougall and Barker, 2011); however, because conservative temperature and absolute salinity have been introduced to oceanography comparatively recently, limiting comparison with historical climatologies and other hydrographic data sets, potential temperature and practical salinity are also provided. The profile data are linearly interpolated to 41 dbar levels, ranging from 50 to $2000 \mathrm{dbar}$ (Table 1). The upper $50 \mathrm{dbar}$ are omitted from the data set due to strong seasonal variability and sea-ice interaction. The 41 levels are spread such that the intervals are smallest at $50 \mathrm{~m}(10 \mathrm{~m})$ and increase to a maximum of $100 \mathrm{~m}$ spacing below $800 \mathrm{~m}$. The levels themselves were arbitrarily selected. Objective mapping is applied to the entire data set spanning from December 2001 to March 2013, as well as to three subsets, where the data are split according to the following time periods: (1) 2001-2005, (2) 2006-2009 and (3) 2010-2013 (hereafter TP1, TP2 and TP3 respectively). This splits the data set into roughly equal time spans. Note
Table 1. Standardized pressure levels (dbar) to which all profiles are linearly interpolated.

\begin{tabular}{rrrrrr}
\hline \multicolumn{5}{c}{ Standardized pressure levels (dbar) } \\
\hline $\mathbf{1}$ & 50 & $\mathbf{1 5}$ & 280 & $\mathbf{2 9}$ & 800 \\
$\mathbf{2}$ & 60 & $\mathbf{1 6}$ & 300 & $\mathbf{3 0}$ & 900 \\
$\mathbf{3}$ & 70 & $\mathbf{1 7}$ & 320 & $\mathbf{3 1}$ & 1000 \\
$\mathbf{4}$ & 80 & $\mathbf{1 8}$ & 340 & $\mathbf{3 2}$ & 1100 \\
$\mathbf{5}$ & 90 & $\mathbf{1 9}$ & 360 & $\mathbf{3 3}$ & 1200 \\
$\mathbf{6}$ & 100 & $\mathbf{2 0}$ & 380 & $\mathbf{3 4}$ & 1300 \\
$\mathbf{7}$ & 120 & $\mathbf{2 1}$ & 400 & $\mathbf{3 5}$ & 1400 \\
$\mathbf{8}$ & 140 & $\mathbf{2 2}$ & 450 & $\mathbf{3 6}$ & 1500 \\
$\mathbf{9}$ & 160 & $\mathbf{2 3}$ & 500 & $\mathbf{3 7}$ & 1600 \\
$\mathbf{1 0}$ & 180 & $\mathbf{2 4}$ & 550 & $\mathbf{3 8}$ & 1700 \\
$\mathbf{1 1}$ & 200 & $\mathbf{2 5}$ & 600 & $\mathbf{3 9}$ & 1800 \\
$\mathbf{1 2}$ & 220 & $\mathbf{2 6}$ & 650 & $\mathbf{4 0}$ & 1900 \\
$\mathbf{1 3}$ & 240 & $\mathbf{2 7}$ & 700 & $\mathbf{4 1}$ & 2000 \\
$\mathbf{1 4}$ & 260 & $\mathbf{2 8}$ & 750 & & \\
\hline
\end{tabular}

that the gridded fields of potential temperature and practical salinity include data up to 21 October 2014; however, with delayed-mode data availability at the time of data set creation, this provides only a small addition of about 47 profiles within the defined Weddell Gyre region, all of which are north of $62^{\circ} \mathrm{N}$.

\section{Methods}

\subsection{Sub-surface temperature maximum}

In addition to temperature and salinity maps of the 41 pressure levels in Table 1, maps of temperature, salinity and pressure are also generated at the level of the sub-surface temperature maximum (hereafter Tmax). Examples of typical temperature-pressure profiles from Argo float data within the Weddell Gyre are shown in Fig. 5. The sub-surface temperature maxima are clearly marked. There are two reasons for providing the Tmax. Firstly, it represents the core of incoming Circumpolar Deep Water, which is the main source water (and heat source) feeding the Weddell Gyre. Secondly, it is used to define the northern boundary of the Weddell Gyre for the fields mapped onto pressure surfaces. The northern boundary is defined by the Weddell Front, which is controlled by the topography of the sub-surface ridges (e.g. the North Weddell Ridge) but is not fixed in position due to strong interactions between the Antarctic Circumpolar Current to the north and the Weddell Gyre flow to the south. The Weddell Front can be located where the core of warm water from the Antarctic Circumpolar Current meets the relatively cold subsurface water of the Weddell Gyre (Fahrbach et al., 2011). Thus, the point at which the meridional gradient of the Tmax is largest is the latitude at which the Weddell Front is located. This boundary definition removes profiles from outside of the Weddell Gyre when mapping to fixed pressure 


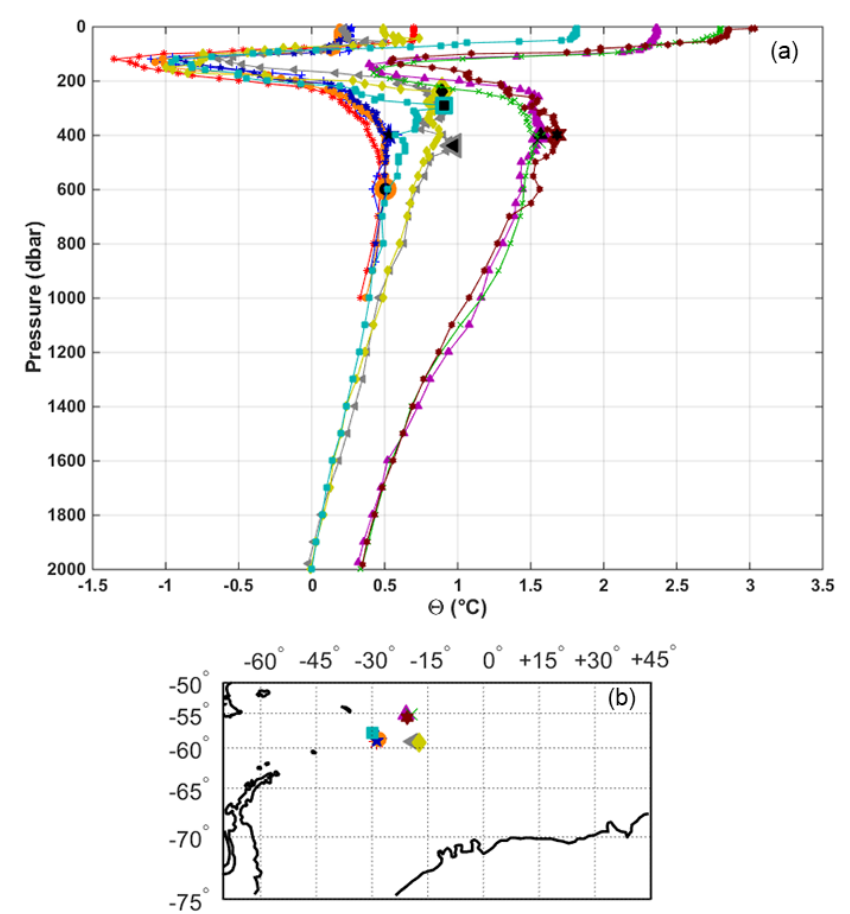

Figure 5. A random sample of pressure (dbar)-conservative temperature $\left({ }^{\circ} \mathrm{C}\right)$ profiles from Argo floats within the regions $15-30^{\circ} \mathrm{W}$ and $55-60^{\circ} \mathrm{S}$ (a) and the corresponding locations of the profiles (b). The sub-surface temperature maximum of each profile is marked with an enlarged symbol.

levels, ensuring that profiles strictly within the gyre itself are selected for each grid point, which provides some security when using large length scales to determine the large-scale mean field of the gyre.

The Tmax is determined by taking the sum of the $z$ scores of temperature and pressure. The $z$ score assigns "scores" to data points based on their deviation from the mean. Using $z$ scores instead of the standard deviations (from which the $z$ scores are calculated) allows for the direct consideration of standard deviations of two different variables: temperature and pressure. Above the Tmax is a sub-surface temperature minimum, which is representative of the water mass known as Winter Water (WW). This minimum is the coldest water at the shallowest depth (which will be at the surface during the winter and migrates to sub-surface level after summer warming at the surface) and can be located by finding the pressure at which the sum of $z$ scores is smallest. The maximum subsurface temperature can then be determined as the maximum temperature below this temperature minimum. This statistical method finds the deepest temperature maximum, thus taking into account seasonal surface warming and is particularly useful when dealing with large data sets with large seasonal surface variability. Computationally, the Tmax is determined as follows:

$$
\begin{aligned}
& X=\operatorname{sum}[z \text { score }(\operatorname{tmp}), z \text { score }(\text { pressure })] \\
& i=\operatorname{find}(X==\min (X)) \\
& \operatorname{Tmax}=\max (\operatorname{tmp}(i: \text { end }))
\end{aligned}
$$

\subsection{Objective mapping}

\subsubsection{Approach}

Due to the irregular nature of the free-drifting profiling float, both in a spatial and temporal context, there are significant challenges regarding the utilization of these data in the creation of statistically robust gridded data sets. One common method in dealing with profile data is the application of optimum interpolation, an adapted form of kriging first developed for application in oceanography by Bretherton et al. (1976), though a similar method was previously applied in a meteorological context (Gandin, 1965). The technique is based on the Gauss-Markov theorem and provides a pointwise estimate of the interpolated field; this estimate is linear and unbiased and is based on the minimization of the expected interpolation error (i.e. it is optimal in the least squares sense; Gandin, 1965; McIntosh, 1990). The method also provides a map of error variance which takes into account the spatial distribution of the data used.

Objective mapping methods have been implemented in a number of studies, providing spatially averaged climatological data sets of observations, as well as for more specific purposes. Wong et al. (2003) and Böhme and Send (2005) have applied the method in a two-stage procedure in order to calibrate float profile salinity data, while Rabe et al. (2011) mapped Arctic observation data in order to determine changes in freshwater content. On a global scale, objective mapping has been used to determine the warming of the global upper ocean, as well as other global ocean indicators (Lyman and Johnson, 2008; Lyman et al., 2010; Levitus et al., 2012). However, the limited volume of data at high latitudes is such that when objective mapping has been applied to float data on a global scale, regions south of $\sim 50-60^{\circ} \mathrm{S}$ are poorly represented in the mapping process and are typically the primary cause of discrepancies (e.g. Roemmich and Gilson, 2009; Chang et al., 2009; von Schuckmann and Le Traon, 2011).

Objective mapping methods are typically used in the production of climatologies. The most prominent and recent are the WOA atlases (World Ocean Atlas; Locarcini et al., 2006, 2010, 2013; Antonov et al., 2006, 2010; Zweng et al., 2013), which use a three-pass successive correction method (with the exception of WOA98, which applies a one-pass successive correction; Cressman, 1959; Barnes, 1964, 1994), and the WOCE atlases (World Ocean Circulation Experiment; Gouretski and Koltermann, 2004; Orsi and Whitworth, 2005), which follow the optimum interpolation technique described above. The successive correction method is used in 
WOA in order to avoid the use of second-order statistics due to the paucity of data (Locarcini et al., 2013), while WOCE justify the use of the Gauss-Markov technique by acknowledging that the Gaussian correlation function used is highly arbitrary and results in over-smoothing on small scales (McIntosh, 1990; Gouretski and Koltermann, 2004) but that the successive correction method may yield less consistent results (Sterl, 2001; Gouretski and Koltermann, 2004). Here, the optimum interpolation (or "Gauss-Markov technique") is used. The most notable differences between the mapping method described in the following section and the approach used in the climatologies above are discussed in Sect. 6.1.

In this study, the aim is to provide a broad outlook on the properties across the entire Weddell Gyre. Therefore, the objective mapping omits temporal averaging resulting in maps that represent spatially gridded time composites of the field variables for these time periods. The mapping process is implemented in a two-step procedure, allowing for a step-bystep improvement of the mean field estimate. In the first stage, the first-guess field is the zonal mean, and the covariance is a function of large-scale separation. The resulting field estimate then becomes the first-guess field in the second stage of mapping, where the covariance is a function of small-scale separation, which gives extra weight to closeby data in regions where the data are abundant. In regions of sparse data density, the objective estimate reverts back to the mean guess field and the corresponding mapping error is large. This two-stage method approach reduces the possibility for errors by providing an improved estimate of the firstguess field, which leads to a general reduction in the magnitude of the signal variance, $\left\langle s^{2}\right\rangle$, by which the covariance matrices are scaled.

\subsubsection{Objective mapping}

For each pressure surface, the corresponding temperature and salinity data are extracted from the vertically and linearly interpolated float profiles (for further details refer to Sect. 2). Thus, only vertically interpolated data at the pressure surface which they are to be mapped to are included in the mapping. The extracted data points are objectively mapped onto a regular $1^{\circ} \times\left(1^{\circ} / \cos \left(-65^{\circ}\right)\right)$ grid. This results in grid cells of approximately $110 \mathrm{~km} \times 110 \mathrm{~km}$ at $65^{\circ} \mathrm{S}$ - roughly the central axis of the gyre. For each grid point, $N$ representative

profiles $(x)$ are selected for the mapping procedure (for details regarding the selection procedure, refer to Sect. 3.2.3). The objective estimate of the variable, $X_{g 1}$, at the grid point $g$ is given by Eq. (1a) for stage 1 and Eq. (1b) for stage 2 . The zonal mean, $\bar{x}_{\mathrm{z}}$, is the first-guess field in stage 1 , while the objective estimate from stage 1 becomes the first-guess field used in stage 2 . The term $\omega$ denotes the weighting matrix (Wong et al., 2003).

$X_{g 1}=\bar{x}_{\mathrm{z}}+\omega \cdot\left(x-\bar{x}_{\mathrm{z}}\right)$

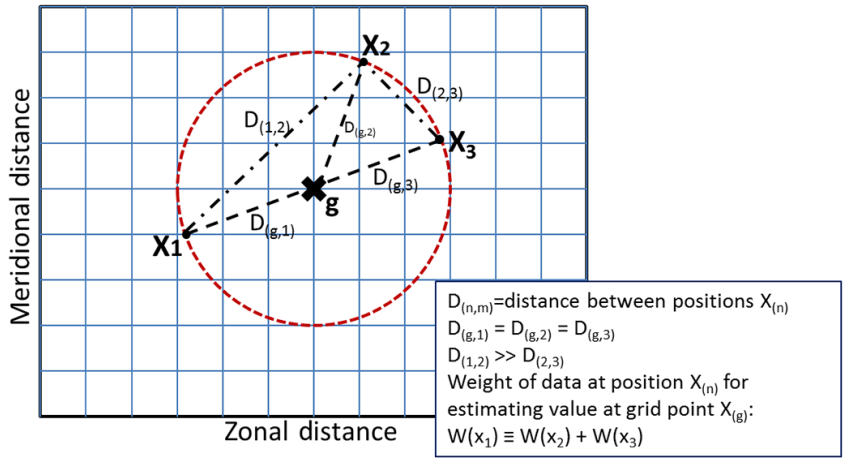

Figure 6. In objective mapping, the profile data are weighted based on their distance $D$ to the grid point $g$, as well their distance to neighbouring profiles. Thus, while profiles $x_{1}, x_{2}$ and $x_{3}$ are all equally distanced from the grid point $g, x_{2}$ and $x_{3}$ are more closely spaced to each other than they are to $x_{1}$. Thus, the weight of $x_{1}$ would be equivalent to the sum of weights for $x_{2}$ and $x_{3}$ (i.e. $\left.W\left(x_{1}\right)=W\left(x_{2}\right)+W\left(x_{3}\right)\right)$.

$X_{g 2}=X_{g 1}+\omega \cdot\left(x-X_{g 1}\right)$

Each profile $x$ is weighted by the horizontal distance $D$ and the fractional distance $F$ in potential vorticity: (1) between the grid point location $g$ and the profile location $i$ and (2) between the neighbouring $N$ profile locations, $i$ and $j$. Thus, the profiles are not just weighted according to their distance to the grid point but also according to neighbouring profiles. As such, where three profiles may have the same distance to a grid point, the profile furthest away from the neighbouring profiles will be assigned the largest weight (for example, refer to Fig. 6). The fractional distance $F$ (Eq. 2) accounts for the cross-isobath separation between two locations. This reflects the influence of potential vorticity and thus bathymetry (Fig. 7) and the Coriolis force (and therefore changes in latitude); potential vorticity strongly influences the flow patterns of water masses, which is accounted for by the following equation (Böhme and Send, 2005):

$F=\frac{|\mathrm{PV}(a)-\mathrm{PV}(b)|}{\sqrt{\mathrm{PV}^{2}(a)+\mathrm{PV}^{2}(b)}}$,

where $a$ and $b$ represent the locations of grid point $g$ and profile $i$ or the neighbouring $N$ profile pairs, $i$ and $j . \mathrm{PV}$ is the barotropic potential vorticity; $P V=$ $\frac{f}{H}$, where $f$ is the Coriolis parameter and $H$ is the full ocean depth, based on the general bathymetric chart of the oceans (GEBCO; IOC et al., 2003). The distances $D$ and $F$ are scaled by a horizontal length scale $L$ $\left(L_{(\text {stage } 1)}=1000 \mathrm{~km}\right.$ and $\left.L_{(\text {stage 2) }}=500 \mathrm{~km}\right)$ and a crossisobath scale $\phi\left(\phi_{(\text {stage 1) }}=0.5\right.$ and $\left.\phi_{(\text {stage } 2)}=0.25\right)$ respectively. See Sect. 3.2.3 for the reasoning behind the values chosen for $L$ and $\phi$. 


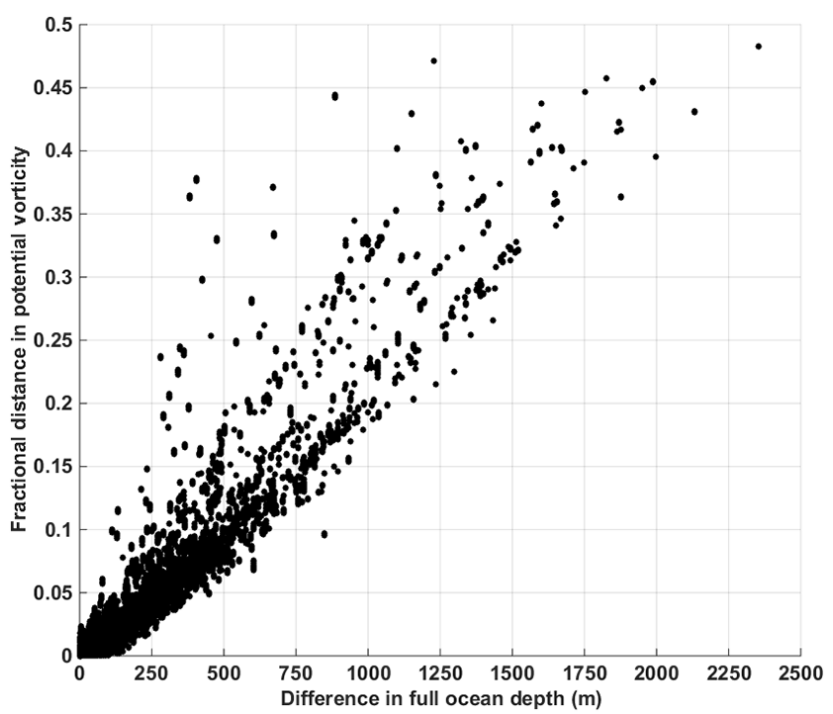

Figure 7. The fractional distance in potential vorticity $(F)$ as a function of the difference in bottom ocean depth $(H)$ between two locations. This is the generalized distance used in the decay scale of the covariance function in order to take into account cross-isobath separation (see text for explanation: Sect. 3.2.2).

The decay scales determined by the distances $D$ and $F$ and their associated length scales are applied in the form of covariance functions in order to determine the weight matrix, $\omega$ (Eq. 3). The data-grid covariance $\left(\boldsymbol{C}_{\mathrm{dg}} ; \mathrm{Eq} .4\right)$ is a function of the distances between the grid point $g$ and the profile location $i$, while the data-data covariance $\left(\mathbf{C}_{\mathrm{dd}} ;\right.$ Eq. 5$)$ is a function of the distance between the $N$ neighbouring profiles, $i$ and $j$. Thus, for every grid point, while $\boldsymbol{C}_{\mathrm{dg}}$ is a $1 \times N$ vector, $\mathbf{C}_{\mathrm{dd}}$ is a $N \times N$ matrix. The covariance of the data is assumed to be Gaussian, following Böhme and Send (2005).

$$
\begin{aligned}
& \omega=\boldsymbol{C}_{\mathrm{dg}} \cdot\left[\mathbf{C}_{\mathrm{dd}}+I \cdot\left\langle\eta^{2}\right\rangle\right]^{-1} \\
& \boldsymbol{C}_{\mathrm{dg}_{i}}=\left\langle s^{2}\right\rangle \cdot \exp \left\{-\left[\frac{D_{i g}^{2}}{L^{2}}+\frac{F_{i g}^{2}}{\phi^{2}}\right]\right\} \\
& \mathbf{C}_{\mathrm{dd}_{i j}}=\left\langle s^{2}\right\rangle \cdot \exp \left\{-\left[\frac{D_{i j}^{2}}{L^{2}}+\frac{F_{i j}^{2}}{\phi^{2}}\right]\right\} \\
& \left\langle s^{2}\right\rangle=\left(\frac{1}{N}\right) \sum_{i}\left(x_{i}-\bar{X}\right)^{2} \\
& \left\langle\eta^{2}\right\rangle=\left(\frac{1}{2 N}\right) \sum_{i}\left(x_{i}-x_{n}\right)^{2}
\end{aligned}
$$

The covariance functions are scaled by the signal variance, $\left\langle s^{2}\right\rangle$ (Eq. 6). $N$ is the number of profiles used to estimate the value at the grid point. The mean field $\bar{X}$, is the zonal mean in the first mapping stage, while the objective estimate from stage 1 becomes the mean field in the second mapping stage. A random noise signal (i.e. the noise variance), $\left\langle\eta^{2}\right\rangle$ (Eq. 7), is added to the diagonal of the data-data covariance func- tion, where $x_{n}$ is the variable of the profile with the smallest distance to the profile location $i$. This term accounts for the variations between nearby data.

In addition to providing an estimate of the field at locations where there are no data, objective mapping also provides an error variance of the objective estimate. This is taken from the second stage of the mapping:

$\sigma_{g}^{2}=\left\langle s^{2}\right\rangle-\boldsymbol{C}_{\mathrm{dg}} \cdot\left[\mathbf{C}_{\mathrm{dd}}+I \cdot\left\langle\eta^{2}\right\rangle\right]^{-1} \cdot \boldsymbol{C}_{\mathrm{dg}}^{\mathrm{T}}$,

where the superscript $\mathrm{T}$ signifies the transposition of the matrix $\boldsymbol{C}_{\mathrm{dg}}$.

\subsubsection{Choosing appropriate length scales $(L, F)$ and selecting $N$ surrounding data points to a grid point}

In stage 1 of the mapping, the length scales are $L=1000 \mathrm{~km}$ and $\phi=0.5$, while in the second mapping stage, in order to give extra weight to nearby data points, $L=500 \mathrm{~km}$ and $\phi=0.25$. Thus, a factor of 4 in the difference $f / H$ is equivalent to a $500 \mathrm{~km}$ horizontal separation in the separation parameter, the decay scale used in the covariance functions (Hadfield et al., 2007). The performance of the objective mapping is sensitive to the length scales used in the correlation function. For a successful and accurate mapping of the field of variables, the applied length scales need to be larger than the minimum distance between data points. Otherwise, the mapped estimate will revert to the mean first-guess field used in the mapping, and the resulting mapping error will be large. In order to estimate suitable length scales for the mapping, the percentage of grid points with at least 40 data points within certain distances are calculated in a similar manner to Hadfield et al. (2007). The results are shown in Fig. 8. The minimum distance at which $100 \%$ of the grid points have at least 40 data points for the entire time series is $1000 \mathrm{~km}$. However, while the percentage remains high (about 99\%) for TP2 and TP3, the percentage decreases to about $95 \%$ for TP1. At $500 \mathrm{~km}$, about $95 \%$ of the grid points have 40 or more data points for the entire time period; about 75, 93 and $90 \%$ of the grid points have more than 40 data points within $500 \mathrm{~km}$ for the time periods TP1, TP2 and TP3 respectively. This value rapidly decreases for distances less than $500 \mathrm{~km}$. Therefore, $1000 \mathrm{~km}$ is used for the large length scale in the first mapping stage and $500 \mathrm{~km}$ is the small length scale $L$ used in the second mapping stage.

The number of data points $(N)$ used in the calculation of the field estimate was set to 40, a necessary limitation to cope with constraints in computational power. The decay scale of the data-grid covariance function $\left(D_{i g}^{2} / L^{2}+\right.$ $\left.F_{i g}^{2} / \phi^{2}\right)$ was applied to the data with the large length scales of stage $1(L=1000 \mathrm{~km}$ and $\phi=0.5)$, and all corresponding data points for which the decay scale was larger than 1 were filtered out (i.e. only data within the e-folding scale of the covariance function were selected; $D_{i g}^{2} / L^{2}+F_{i g}^{2} / \phi^{2}<1$ ). Where more than 40 profiles were available within the decay 


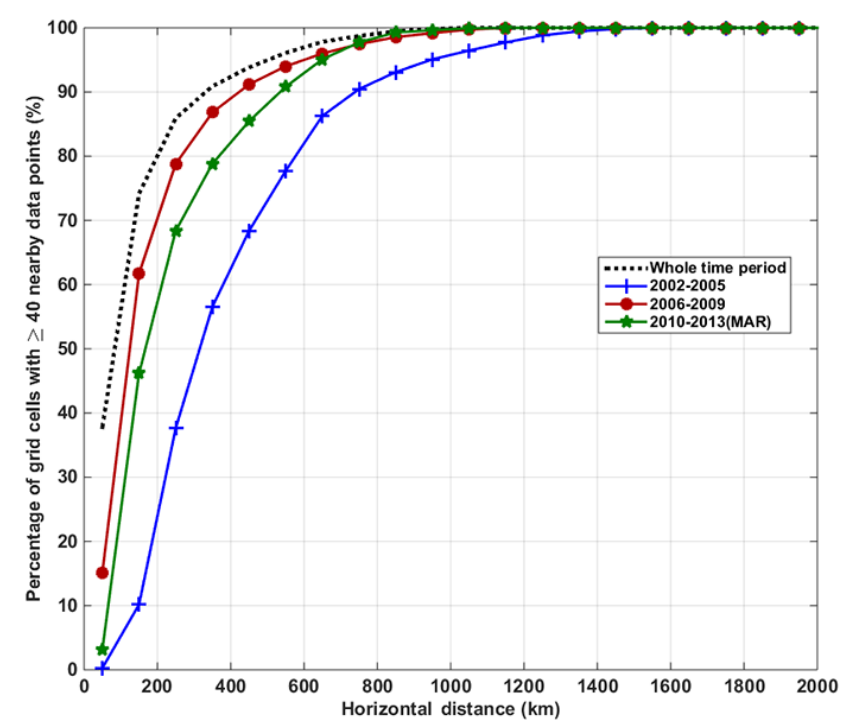

Figure 8. The percentage of grid cells with at least 40 profiles within areas of different radii, for different horizontal distances $(\mathrm{km})$.

scale limit, data were sub-selected by the shortest possible distance to the grid point (i.e. smallest decay scale values). Figure 9 demonstrates the influence of incorporating a crossisobathic separation factor into the decay scale. The contours show the field of influence about a grid point at $71^{\circ} \mathrm{S}, 15^{\circ} \mathrm{W}$ (i.e. the e-folding scale); this field is circular when the decay scale is based purely on the horizontal separation between grid point and profile locations (Fig. 9a) and elongates along lines of constant potential vorticity when the cross-isobathic separation factor is incorporated (Fig. 9b). Figure 10 shows the influence of the cross-isobathic separation factor for a grid point close to the $2000 \mathrm{~m}$ contour line. Therefore, it is possible to use first principals of physical oceanography (as a water parcel is more likely to travel along lines of constant potential vorticity) to sensibly extrapolate to regions of sparse data coverage, so long as there is little variation in bottom bathymetry (the resulting mapping error will be large in areas of complex bathymetry, regions which consequently show dense contouring of potential vorticity).

At first, the mapping process was carried out for the Tmax. The resulting field of conservative temperature was used to determine the northern boundary of the gyre: for each longitudinal bin, the latitude at which the sub-surface temperature is more than $2{ }^{\circ} \mathrm{C}$ is masked. Following this, the latitude at which the meridional sub-surface temperature gradient is largest is defined as the position of the Weddell Front. All grid cells north of this latitude are masked in the following objective mapping processes. This ensures the $N$ profiles for any grid point are selected from within the Weddell Gyre. The mapping process is then carried out for 41 pressure surfaces, ranging from 50 to $2000 \mathrm{dbar}$.
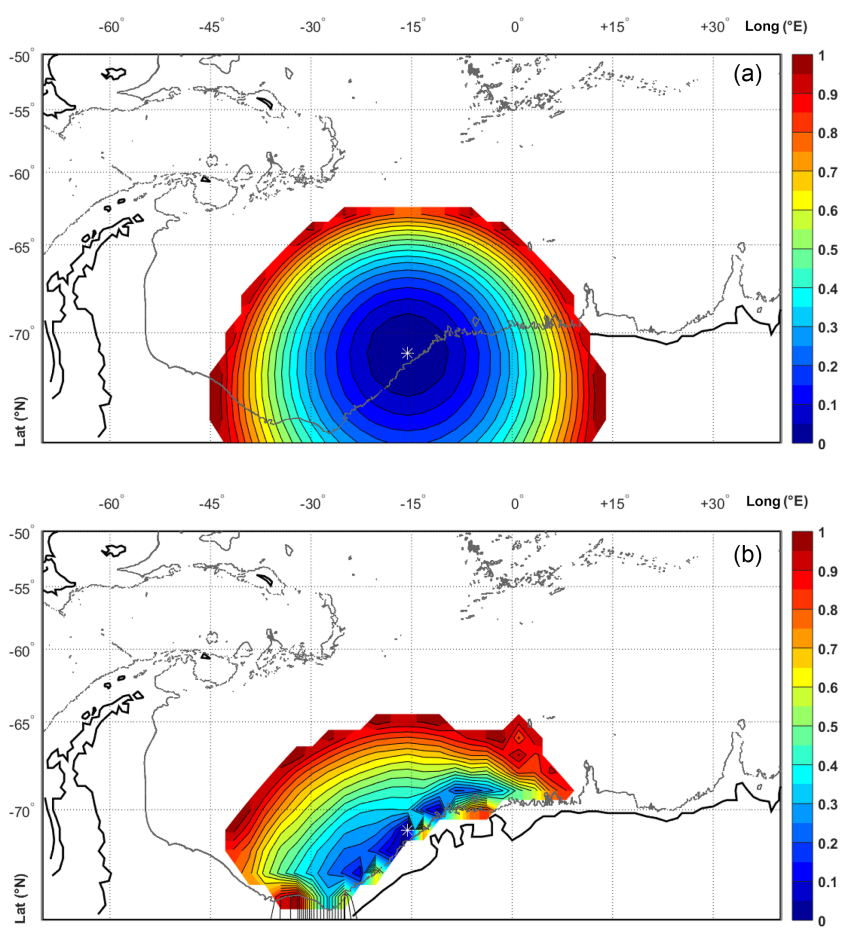

Figure 9. The e-folding decay scale for a grid point at $\sim 15^{\circ} \mathrm{E}$, $71^{\circ} \mathrm{S}$ with (a) only a horizontal component (i.e. $\exp \left\{-\left[D^{2} / L^{2}\right]\right\}$ ) and (b) with the cross-isobathic separation factor as the second component of the decay scale (i.e. $\exp \left\{-\left[D^{2} / L^{2}+F^{2} / \Phi^{2}\right]\right\}$ ). See Sect. 3.2 for explanation. The grey contour shows the $2000 \mathrm{~m}$ isobath.

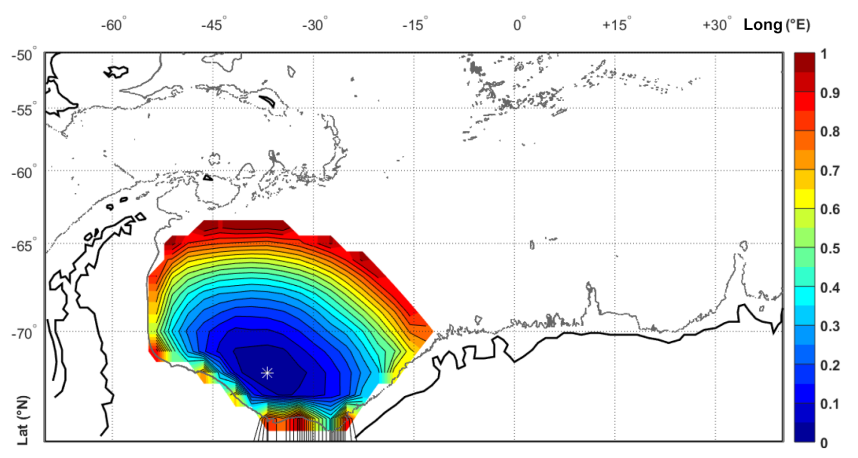

Figure 10. The e-folding decay scale for a grid point at $\sim 38^{\circ} \mathrm{E}$, $72^{\circ} \mathrm{S}$. The grey contour shows the $2000 \mathrm{~m}$ isobath.

\section{Objective mapping performance}

\subsection{Error sources}

Interpolated fields of Argo profile data, such as conservative temperature and pressure at the level of the Tmax (Figs. 11, 12) and the maps presented in Sect. 5, may include several types of error one should be aware of. The first and most obvious is instrument error (Sect. 2); the second is the relative error of the objective interpolation (i.e. mapping error), 

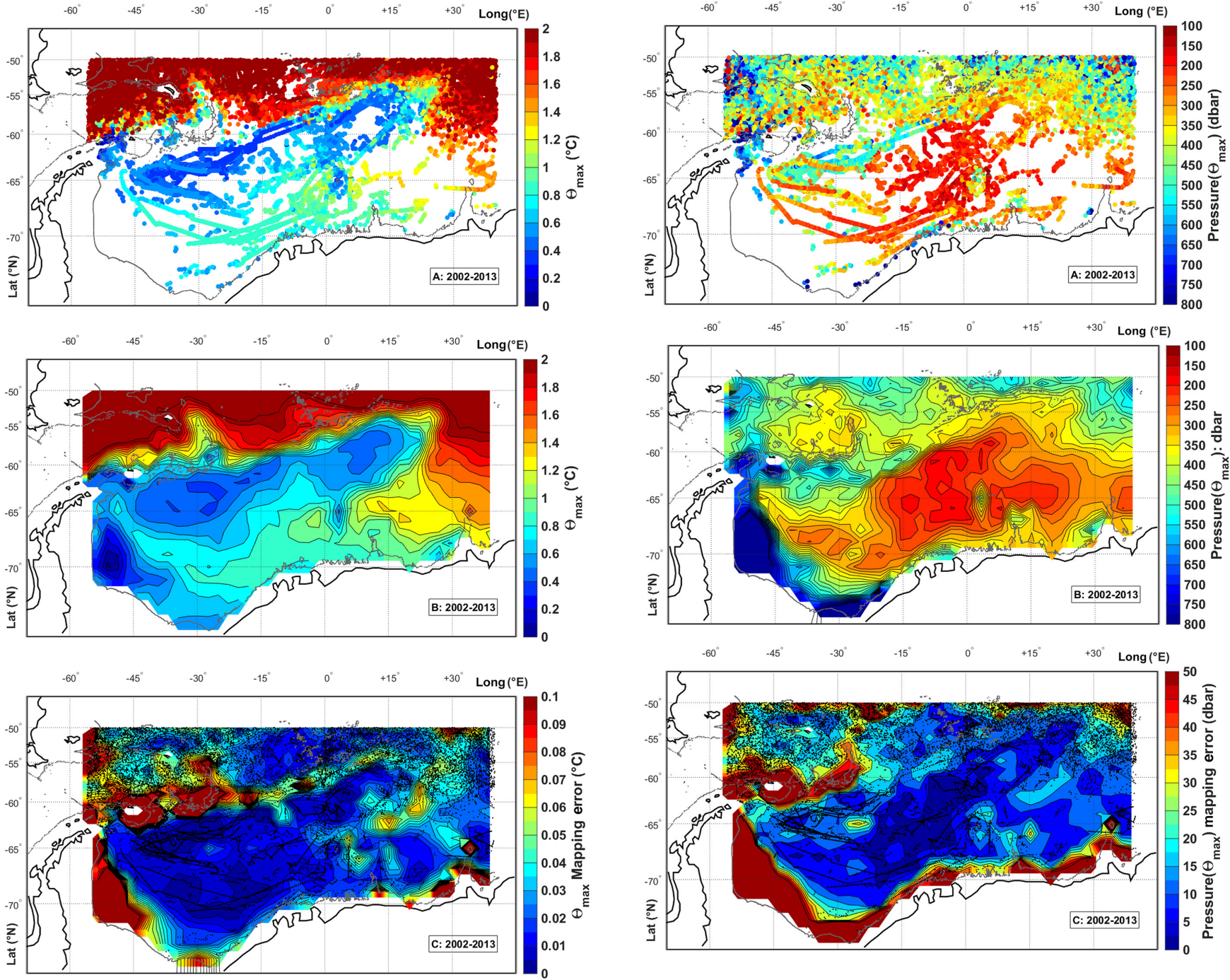

Figure 11. Conservative temperature $\left({ }^{\circ} \mathrm{C}\right)$ at the sub-surface temperature maximum for the entire time period, where panel (a) shows the original float data, panel (b) shows the objectively mapped field and panel (c) shows the mapping error for the mapped field (profile locations are marked as black dots). The grey contour shows the $2000 \mathrm{~m}$ isobath.

which is the square root of the mapped error variance provided $\left(\varepsilon_{g}=\sigma_{g}^{2}\right.$; Eq. 8). The mapped error takes into account the spatial distribution of the input data as well as its signal variance. The mapping error (e.g. Fig. 11c) is the quantitative error value provided and is representative of these factors but should only be taken to represent an estimate of error associated with the specific interpolation method. Indeed, this statistical error is sensitive to length scales used in the covariance functions within the mapping process. The error estimate is inaccurate because the "true" covariance function is unknown. The mapping errors are relatively small within regions of adequate data coverage, with small horizontal gradients of change within the variable to be mapped (so that

Figure 12. Pressure (dbar) at the sub-surface temperature maximum for the entire time period, where panel (a) shows the original float data, panel (b) shows the objectively mapped field and panel (c) shows the mapping error for the mapped field (profile locations are marked as black dots). The grey contour shows the $2000 \mathrm{~m}$ isobath.

the corresponding signal variance across the $N$ data points is small) and where bathymetry is comparatively constant (thus, leading to small variation in planetary potential vorticity). In the western sector of the Gyre interior, the bathymetry is relatively flat and the horizontal gradients of change are relatively small. Therefore, the mapping errors in these regions are also small despite the sparsity of data, with the exception of areas where there are no data points nearby, such as in the far south-west region. In regions with dense data coverage, mapping errors can be high if bottom bathymetry is complex due to the increase in the cross-isobath separation between locations, regardless of horizontal distance. This can be seen along the northern gyre periphery, especially east of about $20^{\circ} \mathrm{W}$ : the data coverage is large and yet 
so are the mapping errors (west of $20^{\circ} \mathrm{W}$ there is a spatial gap over the northern submerged extension of the Antarctic Peninsula, which explains the large errors in this region). The bathymetry is complex due to the presence of submerged ridges and trenches. It is also at the very periphery of the gyre where complex interaction with the Antarctic Circumpolar Current takes place (e.g. Fahrbach et al., 2004; Klatt et al., 2005; Fahrbach et al., 2011; Cisewski et al., 2011). Thus, the objective mapping is poorly representative of these highly variable, complex regions. One way to improve the objective estimate of these regions is to incorporate more suitable correlation length scales as well as a temporal separation factor into the decay scale in Eqs. (4) and (5), such as in Böhme and Send (2005). The correlation length scales would need to match the scale of the true field in order to adequately map these regions. Since these regions typically only occur at the very periphery of the gyre, and due to data sparsity throughout the relatively invariant inner gyre, the correlation length scales are chosen to represent the large-scale field of the entire gyre. Thus, mapping error can be very low in regions of sparse data coverage if bathymetry is constant between the grid point and the station locations and if the difference in water properties between the $N$ neighbouring profiles is also small.

Another source of error which must be taken into consideration concerns the under-ice profiles whose positions are linearly interpolated from the closest known positions of the float, as discussed in Sect. 2 (and shown in Fig. 4). The positions of these floats are clearly flawed, yet the questions is, whether this impacts significantly on the estimated fields. We can make the assumption that floats follow contours of constant planetary potential vorticity (i.e. the $f / H$ contour lines in Fig. 4) in order to maintain constant angular momentum. For the most part, we see that the linear interpolation of the float positions stay within regions of constant $f / H$; thus, the position error can be assumed to be insignificant on the scales at which mapping is applied. The exceptions are the southernmost floats closest to the $2000 \mathrm{~m}$ bathymetric contour (i.e. those that drift with the water that flows along to the coastline), particularly at about 10 and $35^{\circ} \mathrm{E}$, where bathymetric features cause zonal variation in $f / H$. These are the regions along the Antarctic coastline where complex bathymetry, lack of available profiles, and interaction between the flow of the incoming Circumpolar Deep Water and the cold, westward Antarctic coastal current play a role in increasing error and result in relatively increased mapping errors.

A further potential factor influencing the mapped data output is linked to the selection process of $N$ representative profiles for each grid point objective estimate. Many studies incorporate a decision process whereby one third of the profiles is randomly selected from within the e-folding scale of the covariance function in Eqs. (4) and (5) (i.e. $\left.D_{i g}^{2} / L^{2}+F_{i g}^{2} / \phi^{2}<1\right)$, one third is selected on the basis of the smallest distance within the large correlation length scales,
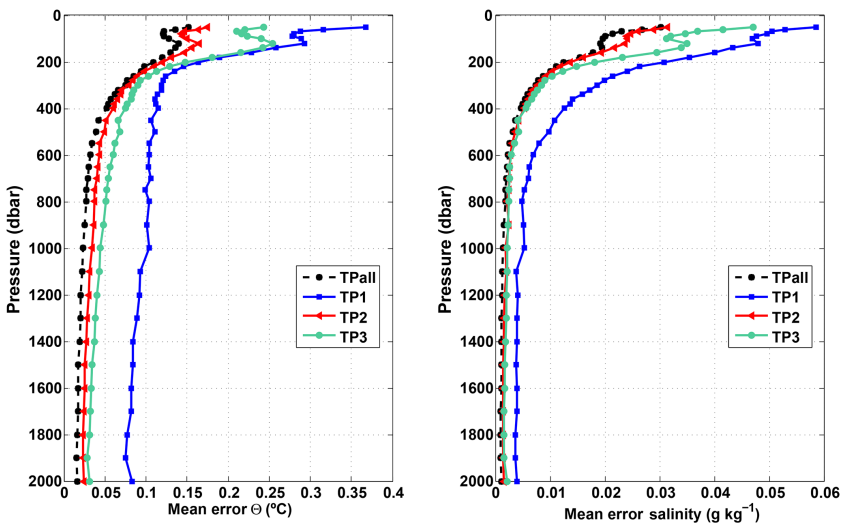

Figure 13. The vertical pressure profile of the area-weighted mean mapping error for (a) conservative temperature $\left({ }^{\circ} \mathrm{C}\right)$ and (b) absolute salinity $\left(\mathrm{g} \mathrm{kg}^{-1}\right)$; for the entire time period (black circles, dashed line), as well as TP1, TP2 and TP3 (the blue squares, red triangles and green circles respectively).

and the remaining third of profiles is selected on the basis of the shortest spatial and temporal separation distances (see, e.g., Böhme and Send, 2005; Rabe et al., 2011). This was done in order to remove potential bias by selecting nearby profiles, such as, for example, those from along repeat hydrographic sections, which are closely spaced in both distance and time. In this study, only data within the e-folding scale of stage 1 are selected, in accordance with the studies above. Where there are more than $N(N=40)$ profiles available, the $N$ profiles with the smallest spatial separations (based on both horizontal distance and planetary potential vorticity separation) are selected. This is justified because the only data utilized come from Argo floats, which are independent of repeat ocean transects. Furthermore, it is a necessary compensation due to limited data availability (and thus the necessity of large correlation scales).

The mapping errors vary according to the corresponding pressure level. Figure 13a and $b$ show the vertical variation in the area-weighted mean mapping error for conservative temperature and absolute salinity respectively. While the error limits are relatively invariant below $400 \mathrm{dbar}$, there is a considerable change in shallower waters. For all time periods, there is a small peak in mean error at about 120 dbar and a small minimum at about $70-90 \mathrm{dbar}$ for temperature. The features are also present in salinity but to a much lesser extent when the peaks are less clearly defined. This coincides with the region of Winter Water, where the maximum peak occurs at the approximate depth of the lower boundary (see, e.g., Fig. 3 in Behrendt et al., 2011). Thus, seasonal signals may have led to the increase in the mapping errors in the shallower mapped surfaces, which should be taken into account when interpreting the mapped surfaces above $200 \mathrm{dbar}$. 


\subsection{Mapping the sub-surface temperature maximum: two approaches compared}

When mapping to the level of the Tmax, there are two approaches one can take. One approach is to extract the corresponding pressure, temperature and salinity values at the Tmax for every float profile in the data set and map each variable independently. This is the approach outlined in Sect. 3.1. Another approach is to extract the pressure of the Tmax for each float profile and apply objective mapping to the pressure variable alone in order to determine a regular gridded data set of pressure at the level of the Tmax. For each grid point, one then selects the $N$ closest profiles, from which the temperature and salinity values are extracted at the pressure level provided by the mapped field previously determined. Thus, the resulting mapped fields of temperature and salinity are dependent on the mapped pressure of the Tmax rather than on the individual profiles themselves. Both approaches were investigated and compared for the entire time period. The resulting mapped field of temperature and the corresponding mapping error are shown in Fig. $11 \mathrm{~b}$, c for the first approach and in Fig. 14 for the second approach. The mapped temperature fields for the two approaches are similar. The differences between the two temperature maps are less than $0.15^{\circ} \mathrm{C}$ throughout the Weddell Gyre, with the exception of regions at the gyre periphery where the differences can be as high as $0.4^{\circ} \mathrm{C}$ (Fig. 15). The first approach typically yields warmer values than the second approach throughout most of the region (hence the map in Fig. 15 is largely negative (blue), as it shows temperature from approach 2 with regard to temperature from approach 1). The second approach leads to slightly larger mapping errors, in particular along the Antarctic coastline. Thus, the first approach, where the temperature, salinity and pressure of the Tmax are independently mapped, is the approach followed in this study. Taking temperature as an example, for the first approach, at any one grid point, the mapped temperature is mapped from the temperature of the Tmax of individual profiles, and thus the $N$ data points could all have differing pressures, but all represent that same Tmax value. Thus the individual pressures are a deviation from the objectively weighted mean pressure. The second approach however, by taking the temperature values of the $N$ profiles at the level of the mapped Tmax pressure, all have the same pressure; however, they are not necessarily at the actual Tmax of their corresponding profiles but rather represent a deviation from the objectively weighted mean temperature of all $N$ profiles. Thus, while the mapping error is largely based on both horizontal length scales and planetary potential vorticity separation, the differences between the methods described above (Fig. 15) could be interpreted as an error estimate of the variability in the vertical range of the Tmax that can be attributed to small-scale processes (e.g. to internal waves, tides, temporal uncertainties) that are ultimately smoothed out in the mapping process. If this interpretation were to hold true, the mapping error due to
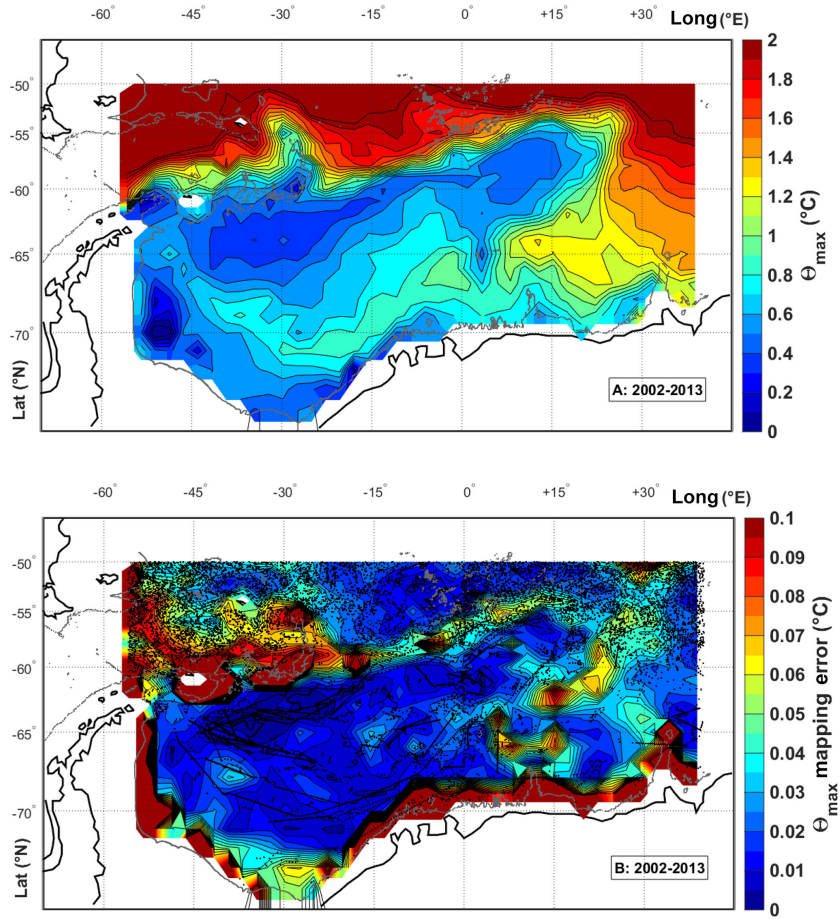

Figure 14. Conservative temperature $\left({ }^{\circ} \mathrm{C}\right)$ at the sub-surface temperature maximum for the entire time period, where panel (a) shows the objectively mapped field based on the second approach (i.e. using the mapped pressure of the sub-surface temperature maximum to extract the temperature data points). The mapping error is shown in panel (b); profile locations are marked as black dots. For more details, refer to Sect. 4.2. The grey contour shows the $2000 \mathrm{~m}$ isobath.

large-scale smoothing would be $0.15^{\circ} \mathrm{C}$ or less for the majority of the Weddell Gyre and would increase to as much as $0.4^{\circ} \mathrm{C}$ in regions of high variability such as north of the western periphery or in regions of no data such as in the far west of the gyre for temperature at the level of the Tmax. We can assume that this estimate would increase for pressure levels above the Tmax and significantly decrease below the Tmax based on Fig. 13. As these error estimates are open to interpretation, they are not included in the final mapped error estimates. Furthermore, these errors also apply to the field variables mapped onto standard pressure levels. However, the errors would be reduced as the input data are interpolated to standardized pressure levels prior to interpolation which removes small-scale instabilities.

The mapping error of pressure at the level of the Tmax (Fig. 12c) has the largest corresponding mapping errors of all mapped surfaces, ranging from $5 \mathrm{~m}$ within the gyre interior to an excess of $50 \mathrm{~m}$ at the coast and in the north-west gyre periphery, directly over submerged mountain ridges that extend from the Antarctic Peninsula. This is because it is subjective to allocate a specific point at which the temperature has reached its maximum in many of the profiles, while the 


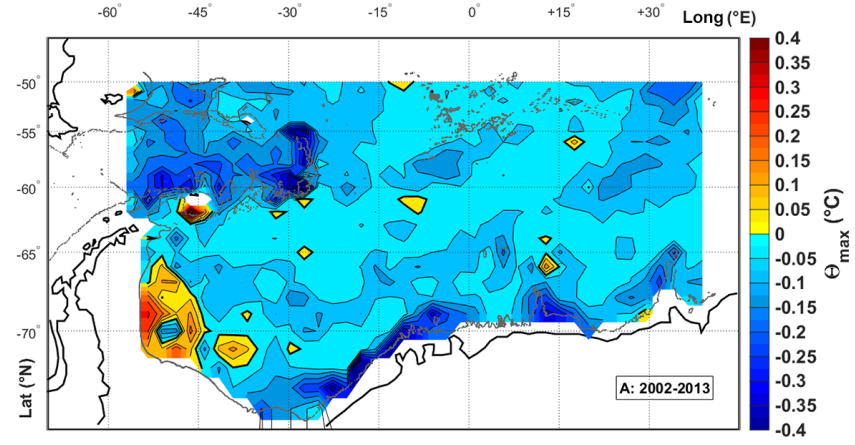

Figure 15. Comparing methods of mapping the sub-surface temperature maximum: this map shows the temperature difference $\left({ }^{\circ} \mathrm{C}\right)$ where the output in the first approach in Fig. 11b is subtracted from the output of the second approach in Fig. 14a. Bold contour lines at $0{ }^{\circ} \mathrm{C}$. The grey contour shows the $2000 \mathrm{~m}$ isobath.

temperature values themselves differ only slightly. Although a statistical method is employed here (see Sect. 3.1), the processes that influence the position of the Tmax are too complex for the method to be extremely accurate, and the number of profiles are too numerous to identify each peak manually. Some profiles do not have a pronounced Tmax. The peak temperature then occurs with a small vertical gradient, so a small change in temperature could shift the peak temperature by hundreds of metres. Thus, while the mapping of the Tmax is relatively successful, caution needs to be exercised when considering the pressure at the level of the Tmax. It is primarily for this reason that the second approach described above was not used in the mapping process.

\subsection{Objective mapping to float profile locations}

In addition to objectively mapping Argo float data to a grid to create a spatially regular field of data variables, the profile data were also objectively mapped to the locations of the profiles themselves, in order to assess the performance of the objective mapping procedure. It is important to note that the resulting maps are not expected to precisely match the profile data, due to the assumption of noise in the data set $\left(\left\langle\eta^{2}\right\rangle\right.$; Eq. 7). While the objective mapping was carried out at the level of the Tmax as well as at $800 \mathrm{dbar}$, only the latter is presented here. Figure 16a shows the original profile data of conservative temperature at $800 \mathrm{dbar}$ for the entire time period. Figure $16 \mathrm{~b}$ shows the objectively mapped field estimate, mapped to the profile locations, while Fig. 16c shows the difference, where the mapped profile data has been subtracted from the original data (i.e. Fig. 16a minus Fig. 16b). The mapping process performs well particularly within the gyre centre, where the differences for the profile locations within the gyre are less than $\pm 0.2^{\circ} \mathrm{C}$ and most often less than $0.1^{\circ} \mathrm{C}$. The differences are larger north of the gyre (mostly north of $60^{\circ} \mathrm{S}$ ), especially in the bathymetrically complex region west of $15^{\circ} \mathrm{W}$ (i.e. approaching the Scotia Sea). This is
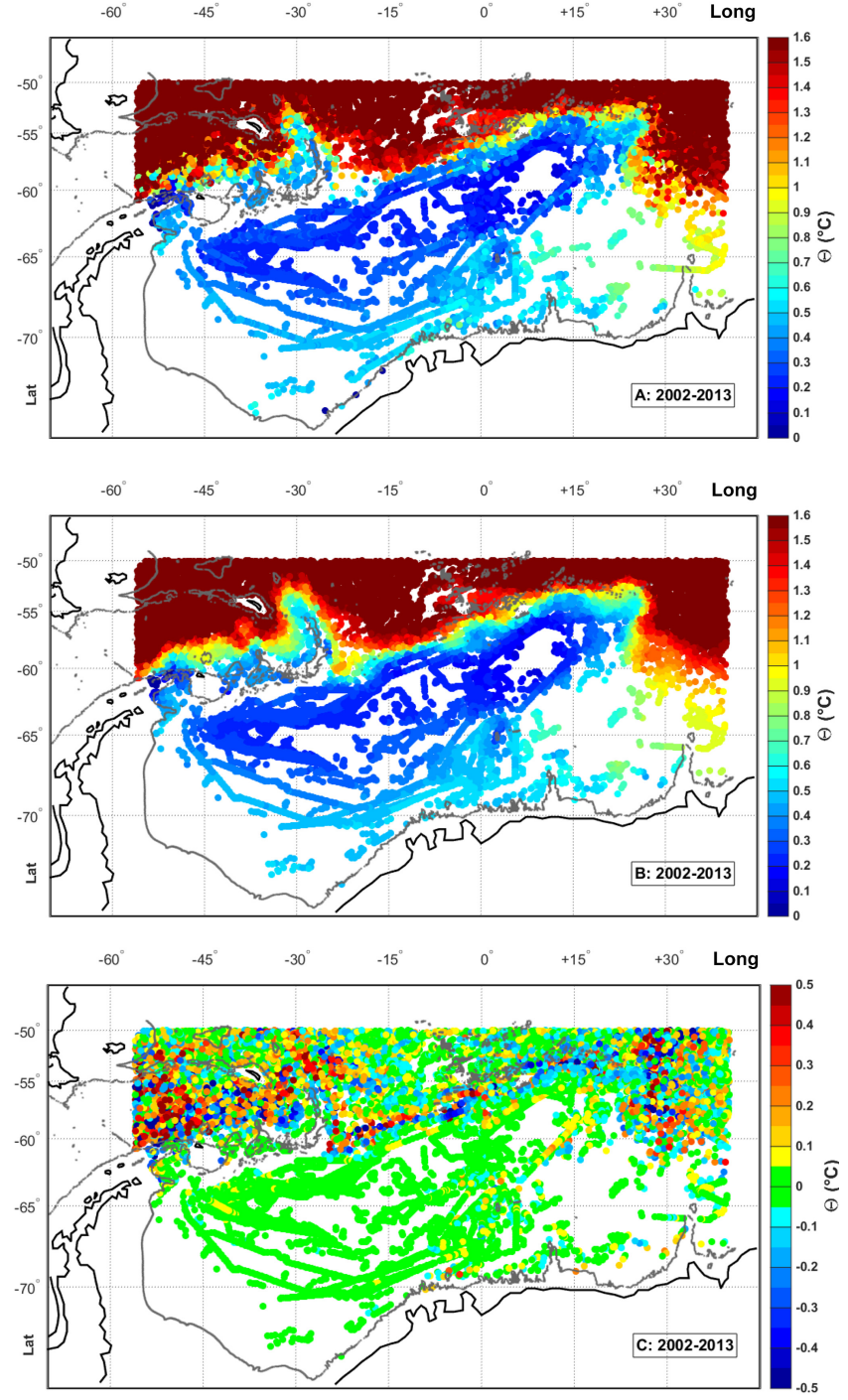

Figure 16. Conservative temperature $\left({ }^{\circ} \mathrm{C}\right)$ at $800 \mathrm{dbar}$ for the entire time period, where panel (a) shows the original float data, panel (b) shows the float data objectively mapped to the profile locations and panel (c) shows the difference where the output in panel (b) is subtracted from the original data in panel (a). The grey contour shows the $2000 \mathrm{~m}$ isobath.

outside of the Weddell Gyre region, but may influence the accuracy of the northern boundary of the gyre. Taking into account all data points shown in Fig. 16c, $87 \%$ of the data points have differences between the original data and the mapped data that are within $\pm 0.2^{\circ} \mathrm{C}$ (Fig. 17a). Furthermore, by considering only profiles within the gyre itself (using the northern boundary definition described in Sect. 2.2), $89 \%$ of the mapped data points differ from the original data points by $\pm 0.2{ }^{\circ} \mathrm{C}$ (Fig. $17 \mathrm{~b} ; 83 \%$ are within $\pm 0.15^{\circ} \mathrm{C}$ ). Regarding temperature at the Tmax (Fig. 18), $82 \%$ of the mapped data points differ from the original data by $\pm 0.2^{\circ} \mathrm{C}$ at most for the entire data set $(84 \%$ when looking at profiles within 

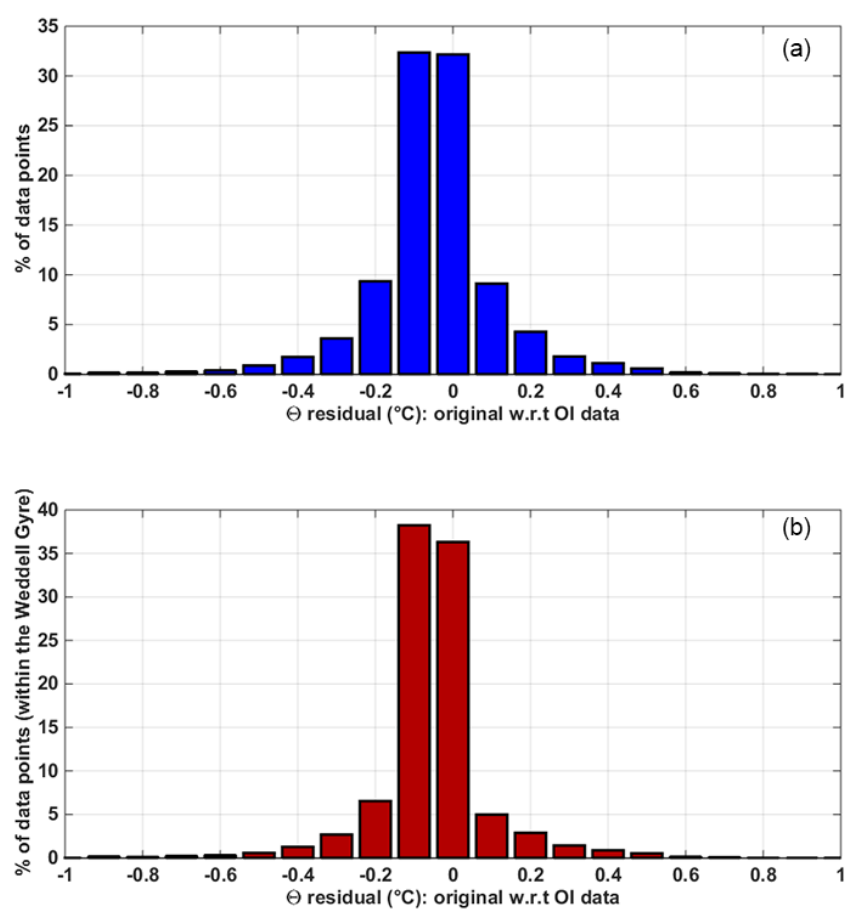

Figure 17. A histogram showing the percentage of data points binned by temperature residuals $\left({ }^{\circ} \mathrm{C}\right)$ at $800 \mathrm{dbar}$, where the float data objectively mapped to the profile locations (i.e. Fig. 16b) are subtracted from the original profile data points (i.e. Fig. 16a), for (a) the entire data set and (b) for those data points within the "defined" Weddell Gyre region only.

the Weddell Gyre only; Fig. 18b). Within the gyre, the $84 \%$ of those Tmax data points differ by $\pm 0.15^{\circ} \mathrm{C}$ at most. Lastly, for pressure at the Tmax, $77 \%$ of the mapped data points differ from the original data points by $\pm 100 \mathrm{~m}$ (Fig. 19a); this value increases to $84 \%$ when considering only those profiles within the Weddell Gyre (Fig. 19b). These values could be interpreted as an estimation of small-scale noise smoothed out through the mapping process, which is generally less than $0.2{ }^{\circ} \mathrm{C}$ and indeed within $0.15^{\circ} \mathrm{C}$ for over $80 \%$ of the data points. This is also the general temperature difference between the two methods of mapping temperature at the Tmax (Sect. 4.2). Again, as these values are interpreted values, they are excluded from the mapping error but are discussed here to emphasize caution regarding possible interpolation errors.

\section{Results}

The following section presents the main features of the gridded fields of data through mapped surfaces at the Tmax and of the isobaric surface at $800 \mathrm{dbar}$, which is the depth at which the Argo floats drift, a level generally understood to be fully within the source water mass of WDW (Fahrbach et al., 2011). Further results extracted from the gridded data are presented in Sect. 6.
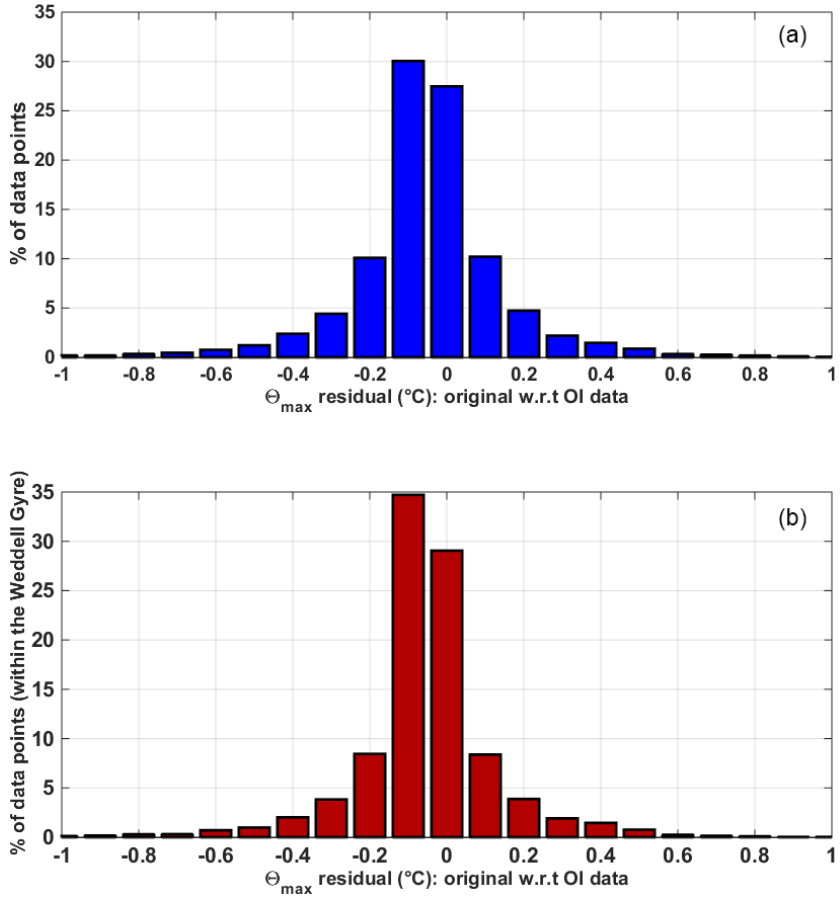

Figure 18. The percentage of data points binned by temperature residuals $\left({ }^{\circ} \mathrm{C}\right)$ at the sub-surface temperature maximum, where the float data objectively mapped to the profile locations are subtracted from the original profile data points, for (a) the entire data set and (b) for those data points within the defined Weddell Gyre region only.

\subsection{Sub-surface conservative temperature maximum}

A typical feature in the hydrography of polar regions is the presence of a sub-surface temperature maximum, as displayed in Fig. 5, which results from the influx of warmer waters from lower latitudes. The maps in Fig. 11 present conservative temperature, $\Theta$, at the level of the Tmax, for the entire time series. The boundary of the gyre to the north is clear as a sharp transition between warmer temperatures above $2^{\circ} \mathrm{C}$ to the north and cooler temperatures of the gyre below $1{ }^{\circ} \mathrm{C}$ to the south. This boundary reflects the bathymetry of the region, including the northern extension of the gyre at the South Sandwich Trench (just east of $30^{\circ} \mathrm{W}, 53$ to $60^{\circ} \mathrm{S}$ ). The incoming source water of the Circumpolar Deep Water is shown as a core of warm water entering the gyre in the east, in the southern limb of the gyre (at about $65^{\circ} \mathrm{S}$, $30^{\circ} \mathrm{E}$, although caution should be exercised regarding data sparsity in this region; Fig. 11a, c). This warm water cools from about 1.2 to $0.6^{\circ} \mathrm{C}$ as it circulates westwards through the southern limb of the gyre. A double-gyre structure is also suggested, where the secondary gyre occurs in the north-east sector, splitting from the main gyre at about $5^{\circ} \mathrm{W}$; this is in agreement with the literature, which commonly refers to the Weddell Gyre as a double-cell structure (see, e.g., Beckmann et al., 1999; Klatt et al., 2005). The largest mapping errors 

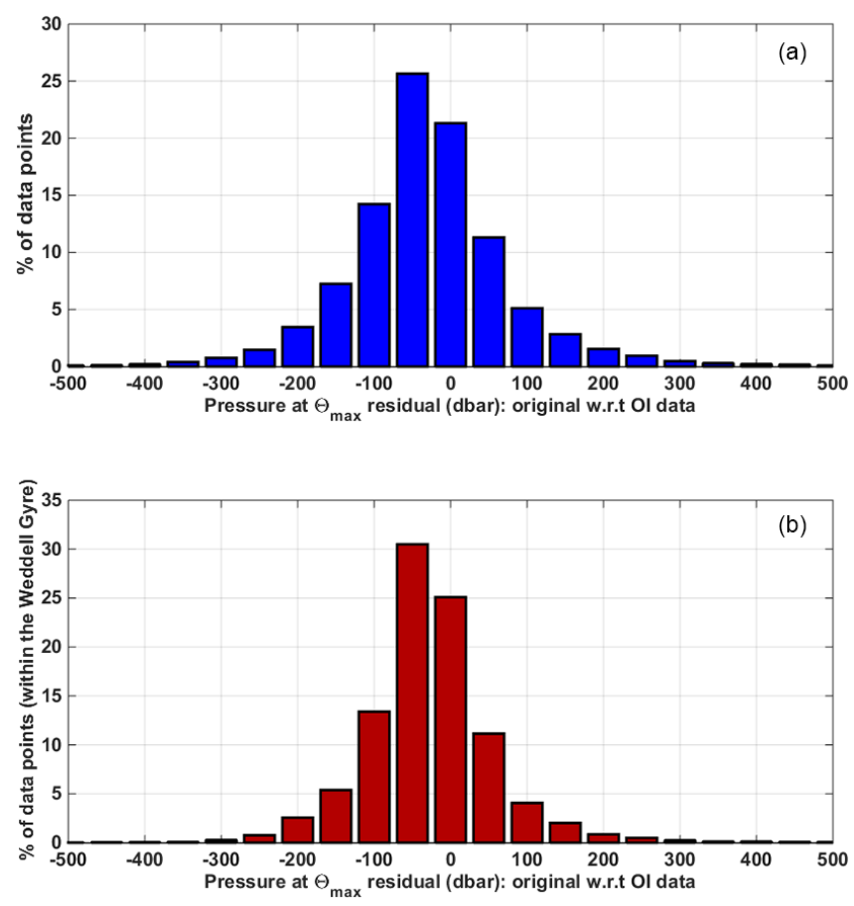

Figure 19. The percentage of data points binned by pressure residuals (dbar) at the level of the sub-surface temperature maximum, where the float data objectively mapped to the profile locations are subtracted from the original profile data points, for (a) the entire data set and (b) for those data points within the defined Weddell Gyre region only.

(Fig. 11c) occur at the gyre boundary in regions of complex bathymetry and to a lesser extent over the eastern sector of the gyre, east of the Prime Meridian where there are considerable spatial gaps in the data distribution. The error is small in the gyre interior, even in regions of especially sparse data density, so long as the bathymetry is unchanging (with the exception of $45-55^{\circ} \mathrm{W}, 64-72^{\circ} \mathrm{S}$, where no profile floats are located). This is because the temperature field is relatively uniform, which results in a small signal variance field, and the bathymetry is constant, which results in minimal change in planetary potential vorticity (Fig. 4). Conversely, pressure at the sub-surface temperature maximum $\left(\operatorname{Pr}_{(\Theta \max }\right)$, Fig. 12) is less stable, hence the large errors (Fig. 12c) at the gyre periphery and along the Antarctic coast. There is a considerable deepening of the sub-surface temperature maximum at about $65^{\circ} \mathrm{S}$, just east of the Prime Meridian, from about $200 \mathrm{~m}$ in the surrounding region to roughly $400 \mathrm{~m}$, which occurs directly over Maud Rise (note that the mapping error is relatively small in this region due to the large availability of profiles despite the large change in bathymetry). This is in agreement with the literature, which shows the presence of trapped water in a Taylor column over Maud Rise, identifiable by a localized cooler sub-surface temperature maximum in comparison to surrounding regions (Bersch et al., 1992; Muench et al., 2001, and Leach et al., 2011). The sub-
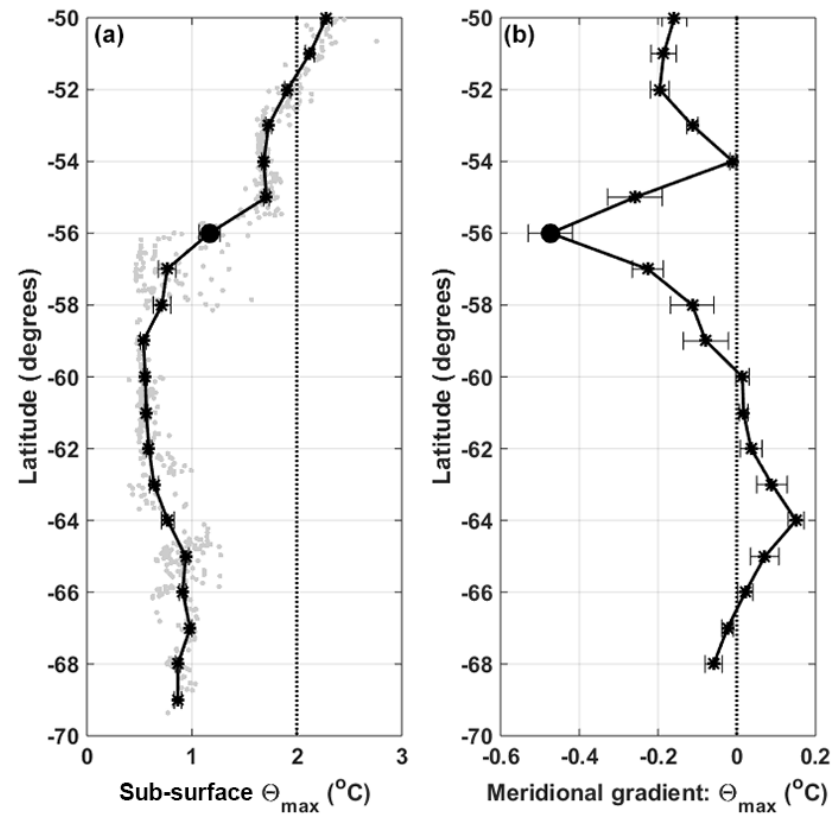

Figure 20. Panel (a): mean meridional temperature distribution $\left({ }^{\circ} \mathrm{C}\right)$ at the sub-surface temperature maximum extracted from the mapped field in Fig. 11b for longitude bins encompassing the Prime Meridian. The meridional gradient of the temperature maximum is shown in panel (b). The large, solid, circular symbols mark where the magnitude of the gradient is largest - this marks the latitude of the northern boundary of the gyre for this longitude. The error bars both in panel (a) and (b) represent the propagation of the mapped errors from each grid cell used in the calculation (i.e. two grid cells, immediately to the east and west of the Prime Meridian). The original profiles within $1^{\circ}$ of the Prime Meridian are shown in grey in panel (a).

surface temperature maximum is shallowest within the gyre centre and deepest towards the gyre peripheries, demonstrating the domed structure associated with the cyclonicity of the gyre.

The mean meridional sub-surface temperature, $\Theta_{(\Theta \max )}$ along the Prime Meridian (as extracted from the gridded data set) is given in Fig. 20a along with the resultant meridional temperature gradient in Fig. 20b. The large dots show the latitude at which the gradient is largest, which occurs at $56^{\circ} \mathrm{S}$ (note: the gradient is negative due to the south-north direction). This is the latitude used to define the northern boundary at the Prime Meridian, which corresponds to the northern boundary used in the long-term analysis of properties at the Prime Meridian in Fahrbach et al. (2011). All grid points north of this latitude are masked from the mapping process for the subsequent isobaric mapped surfaces. 

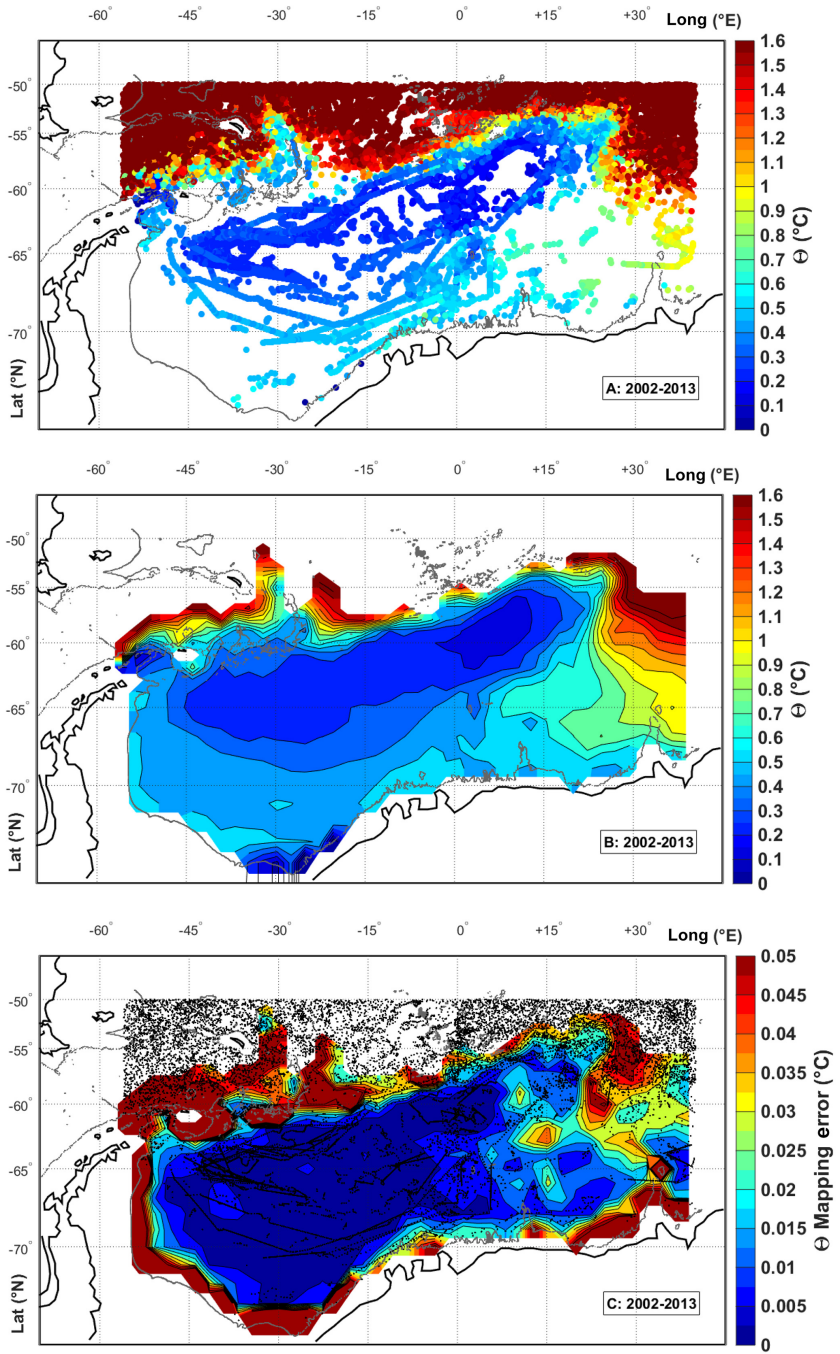

Figure 21. Conservative temperature $\left({ }^{\circ} \mathrm{C}\right)$ at $800 \mathrm{dbar}$ for the entire time period, where panel (a) shows the original float data, panel (b) shows the objectively mapped field and panel (c) shows the mapping error for the mapped field (profile locations are marked as black dots). The grey contour shows the $2000 \mathrm{~m}$ isobath.

\subsection{Conservative temperature and absolute salinity at $800 \mathrm{dbar}$}

Figure $21 \mathrm{a}, \mathrm{b}$ and $\mathrm{c}$ show the original profile data, the mapped field and the associated mapping errors, respectively, of conservative temperature at $800 \mathrm{dbar}$ for the entire time period. Figure 22 shows the same but for absolute salinity, $S_{\mathrm{A}}$. Both fields show the structure of the gyre, where relatively warm, salty water from the north enters the gyre in the southern limb (south of $60^{\circ} \mathrm{S}$ ) at about $30^{\circ} \mathrm{E}$ and gradually cools as it circulates in a clockwise direction throughout the gyre. Note that while the data are sparse in this entry zone, the available stations in Figs. 21a and 22a also show the incoming warm, salty source water. There is a gradual transition from relatively warm, salty water in the south-east sector of the
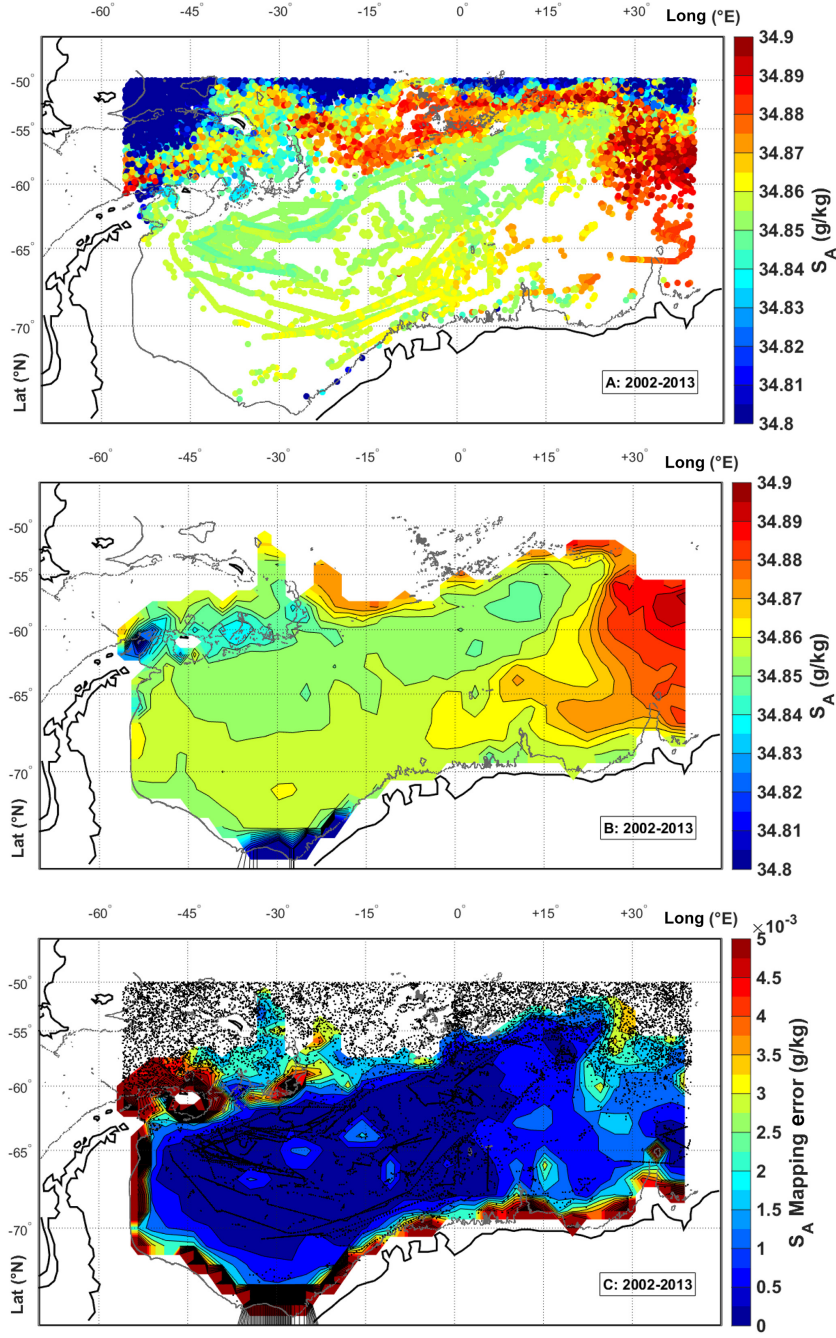

Figure 22. Absolute salinity $\left(\mathrm{g} \mathrm{kg}^{-1}\right)$ at $800 \mathrm{dbar}$ for the entire time period, where panel (a) shows the original float data, panel (b) shows the objectively mapped field and panel (c) shows the mapping error for the mapped field (profile locations are marked as black dots). The grey contour shows the $2000 \mathrm{~m}$ isobath.

gyre, to cooler, fresher water in the western southern limb of the gyre, to even cooler, fresher water in the northern limb of the gyre. The coolest, freshest water at $800 \mathrm{dbar}$ occurs in the east within the northern limb of the gyre. The associated mapping errors for both temperature and salinity are small, in particular at the centre of the gyre, and larger in regions of complex bathymetry at the gyre boundaries. The mapping errors represent the large-scale field (i.e. the assumption is that the resulting fields have been considerably over-smoothed).

\section{Discussion}

The objective mapping performance was investigated in Sect. 4. Here, we expand on performance by (1) comparing the mapping approach to global and major ocean basin cli- 
Table 2. List of climatologies discussed in Sect. 6, along with their corresponding grid resolutions, number of interpolation passes, the first-guess fields and radii of influence for each interpolation pass.

\begin{tabular}{|c|c|c|c|c|c|c|c|}
\hline CODE & Climatology & Grid resolution & $\begin{array}{l}\text { No. } \\
\text { passes }\end{array}$ & $\begin{array}{l}\text { Pass 1: first- } \\
\text { guess field }\end{array}$ & $\begin{array}{l}\text { Pass 1: radius } \\
\text { of influence }\end{array}$ & $\begin{array}{l}\text { Pass 2: radius } \\
\text { of influence }\end{array}$ & $\begin{array}{l}\text { Pass 3: radius } \\
\text { of influence }\end{array}$ \\
\hline HA_SO & $\begin{array}{l}\text { Hydrographic Atlas of the } \\
\text { SO (Olbers et al., 1992) }\end{array}$ & $1^{\circ} \times 1^{\circ}$ & & & & & \\
\hline WOA94 & $\begin{array}{l}\text { World Ocean Atlas } \\
\text { (Levitus et al., 1994) }\end{array}$ & $1^{\circ} \times 1^{\circ}$ & 1 & Zonal mean & $555 \mathrm{~km}$ & & \\
\hline WOA98 & WOA (Antonov et al., 1998) & $1^{\circ} \times 1^{\circ}$ & 3 & Zonal mean & $892 \mathrm{~km}$ & $669 \mathrm{~km}$ & $446 \mathrm{~km}$ \\
\hline WOA01 & Stephens et al. (2001) & $1^{\circ} \times 1^{\circ}$ & 3 & Zonal mean & $892 \mathrm{~km}$ & $669 \mathrm{~km}$ & $446 \mathrm{~km}$ \\
\hline WOA05 & Locarnini et al. (2005) & $1^{\circ} \times 1^{\circ}$ & 3 & Zonal mean & $892 \mathrm{~km}$ & $669 \mathrm{~km}$ & $446 \mathrm{~km}$ \\
\hline WOA09 & Locarnini et al. (2010) & $1^{\circ} \times 1^{\circ}$ & 3 & Zonal mean & $892 \mathrm{~km}$ & $669 \mathrm{~km}$ & $446 \mathrm{~km}$ \\
\hline WOA13 & Locarnini et al. (2013) & $1^{\circ} \times 1^{\circ}$ & 3 & Zonal mean & $892 \mathrm{~km}$ & $669 \mathrm{~km}$ & $446 \mathrm{~km}$ \\
\hline WOA13 & Locarnini et al. (2013) & $\frac{1}{4}^{\circ} \times \frac{1}{4}^{\circ}$ & 3 & Zonal mean & $321 \mathrm{~km}$ & $267 \mathrm{~km}$ & $214 \mathrm{~km}$ \\
\hline WOCE_global & Locarnini et al. (2013) & $1^{\circ} \times 1^{\circ}$ & 1 & $\begin{array}{l}\text { Mean subdomain } \\
\text { within radius of } \\
750 \mathrm{~km}\end{array}$ & $\begin{array}{l}R=450 \mathrm{~km} \text { (open } \\
\text { ocean; }>500 \mathrm{~km} \\
\text { from coast) }\end{array}$ & & \\
\hline WOCE_SO & Orsi and Whitworth (2005) & $24 \times 24 \mathrm{~km}$ & 1 & & $\begin{array}{l}R=666 \times 333 \mathrm{~km} \\
\text { (open ocean } \\
>4000 \mathrm{~m} \text { depth) }\end{array}$ & & \\
\hline WG & & ${ }^{*} 1^{\circ} \times(1 / \cos (-65))^{\circ}$ & 2 & Zonal mean & $\begin{array}{l}R=1000 \mathrm{~km} \\
\Phi=0.5\end{array}$ & $\begin{array}{l}R=500 \mathrm{~km} \\
\Phi=0.25\end{array}$ & \\
\hline
\end{tabular}

* Approximately $110 \mathrm{~km} \times 110 \mathrm{~km}$ along the central gyre axis at $65^{\circ} \mathrm{S}$.

matologies and (2) assessing the resulting gridded fields in the context of what is already known about Weddell Gyre hydrography (an interpretation of data is avoided, as it is beyond the scope of this data paper).

\subsection{Approach to objective mapping - comparison to climatologies}

Climatologies are generally constructed as mean oceanographic fields that represent a reference data set for a given period, which can then be used to derive temporal or spatial change across different scales or periods. Figure 23 shows the different time periods of a group of climatologies, as well as the gridded data sets provided here (hereafter WG_all, WG_TP1, WG_TP2 and WG_TP3, where "all" denotes the entire time period analysis and "TP" denotes the time period subsets). Table 2 provides the full name, regional boundary definitions and citations for each of the climatologies listed in Fig. 23. The closest matching time period to WG_all is WOA13, with a time span of 2005 to 2012 ("WOA13_0512" in Fig. 23); indeed WOA13 is the only climatology that will have incorporated the high-latitude float data of the Weddell Gyre, which provides improved spatial coverage of the upper $2000 \mathrm{~m}$. The WG data sets are representative of smaller time periods, which may be helpful in the cross comparison with ship data and analysis of variability over smaller time periods (although users should exercise caution in the larger errors associated with WG13_TP1 due to data sparsity). The data source for the climatologies listed consists of historical data and more modern, higher-quality data (e.g. WOCE), combining different data types (e.g. ship conductivity-temperaturedepth (CTD) measurements, ship water sample, moorings, buoys, drifters and gliders). The WG data sets provide Argo- only gridded fields, which are therefore independent data sets which may be useful in comparison studies. Furthermore, these data sets demonstrate the potential of Argo in providing upper-ocean reduced-time-span gridded fields, which can only improve in the future as more data become available. By using all (or most) available observations, the climatologies listed have to apply strict and numerous levels of quality control procedures in order to remove poor-quality data. Since such a large amount of data is available for the global ocean as well as for the Southern Ocean, a procedure to reduce the amount of data that goes into the mapping method has to be carried out for every climatology. For example, in WOCE_global, the data are binned into $55 \mathrm{~km}^{2}$ boxes; if more than 4 data points are available, a box average of all binned data points is calculated on density surfaces. Therefore, the input data are a combination of observed data points and box-average data points (Gouretski and Koltermann, 2004). In the WG data sets, data sparsity is the largest limitation, and therefore the input data are the original observed values, which have been vertical interpolated to standard pressure levels.

The most prominent differences between the climatologies listed and the WG data sets are the objective mapping method and corresponding weight function. As discussed in Sect. 3.2.1, the WOA climatologies use a successive correction method, while WOCE climatologies use the optimal interpolation method, the same method as applied for the WG data sets. The weight function is dependent on a radius of influence, where data beyond the radius of influence of a grid point have zero weighting. For the WOA climatologies, the mapping method is applied three times, each time with a reduced radius of influence of 892,669 , and $446 \mathrm{~km}$ for the $1^{\circ} \times 1^{\circ}$ grid (the exception is WOA94, which uses a single- 


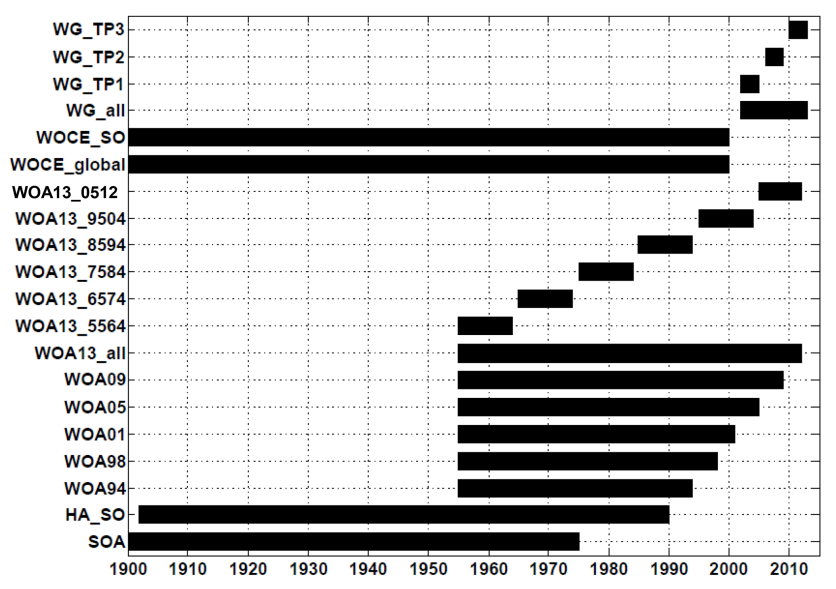

Figure 23. A plot showing the time spans of a list of climatologies, including the time spans of the data set provided here; WG_all represents the gridded fields of the entire time span, while WG_TP1, WG_TP2 and WG_TP3 represent the time spans of the gridded fields for TP1, TP2 and TP3 respectively.

pass successive correction with a radius of $555 \mathrm{~km}$ ). This allows for increased weighting to nearby data points. Note that this applies to the entire global ocean. The WOCE climatologies use the same optimum interpolation method as the WG data sets and the same Gaussian model of the autocorrelation function but with a key difference based on how the influence of bathymetry is incorporated into the correlation function. In the WOCE algorithm, the function, $\exp \left\{-\left[r^{2} / R^{2}\right]\right\}$, where $r$ is the horizontal distance and $R$ is the radius of influence, is the same as the first component of the decay scale in Eqs. (4) and (5). Bathymetry is incorporated into the weighting function by setting the condition that if the grid point is more than $500 \mathrm{~km}$ from the coast, $R=450 \mathrm{~km}$, otherwise $R$ decreases as a function of distance to the coastline. A map of the resulting length scales can be found in Gouretski and Koltermann (2004; Fig. 13). For the WOCE_SO climatology (Orsi and Whitworth, 2005), the radius of influence is elliptical rather than circular, to take into account the fact that currents in the Southern Ocean are dominantly zonal. Furthermore, bathymetry is incorporated by having different radii of influence according to bottom depth. So for example, $R$ is an ellipse of $666 \mathrm{~km} \times 333 \mathrm{~km}$ in the zonal-meridional direction where the bottom depth is larger than $4000 \mathrm{~m}$. In comparison, the WG method incorporates an additional component into the decay scale, which is the cross-isobath separation factor $\left(F^{2} / \Phi^{2}\right.$ in Eqs. 4 and 5), which accounts for changes in planetary potential vorticity and thus provides a more detailed inclusion of bathymetry (and latitude, consequently taking into account the zonally dominated flow). The way this impacts the radius of influence is illustrated in Figs. 9 and 10, while the level of detail of the bathymetry factor is seen by looking at the $f / H$ contours in Fig. 4. Another key difference between the WOCE climatologies and the WG data is the first-
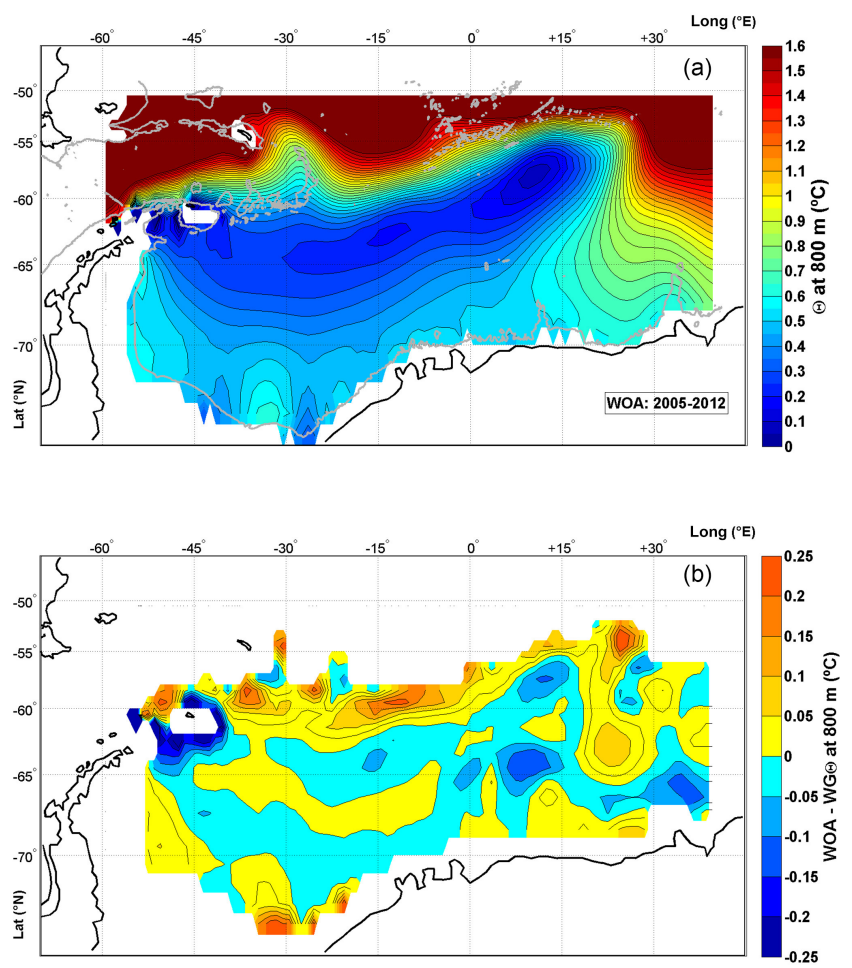

Figure 24. Conservative temperature $\left({ }^{\circ} \mathrm{C}\right)$ at $800 \mathrm{~m}$ from the WOA13 climatology during 2005 to 2012. (i.e. WOA0512 in Fig. 23). Panel (b) shows the difference with the entire time span of the data set provided, i.e. WOA0512 minus WG_all. The grey contour shows the $2000 \mathrm{~m}$ isobath.

guess field and pass number (Table 2). The WOCE climatology takes the first-guess field as the mean of the subdomain in which the radius of influence is $750 \mathrm{~km}$, and then the $N$ closest observations are selected for the mapping $(N=150)$. Mapping is carried out once. In the WG maps, a two-pass optimal interpolation is applied, where the zonal mean is the first-guess field of the first pass and the length scales $D$ and $\Phi$ are $1000 \mathrm{~km}$ and 0.5 respectively, while the output becomes the first-guess field for the second pass, in which the length scales are reduced to $500 \mathrm{~km}$ and 0.25 in order to place extra weighting on the closest data points.

To summarize, all climatologies incorporate a large amount of varying data sources over long periods of time, whereas the WG data constitute an independent Argo-only data set over relatively shorter time periods. The input data for the climatologies listed are typically a combination of observed data in sparse-data-coverage regions and boxaveraged data elsewhere, whereas the WG input data consist of vertically interpolated observed values only. While the climatologies listed contribute to incorporating the influence of bathymetry on the radius of influence by adjusting the radius based on distance to coastline (WOCE) or bottom depth and radius shape (WOCE_SO), the WG mapping incorporates cross-isobathic separation and thus accounts for bathymetry 

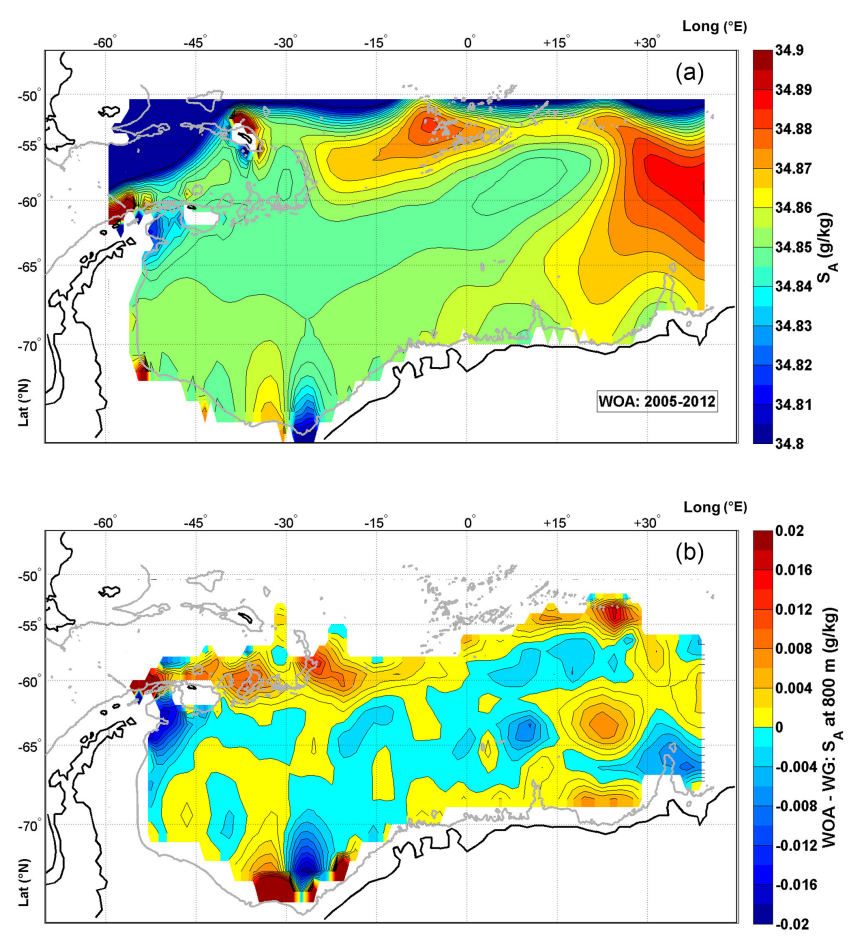

Figure 25. Absolute salinity $\left(\mathrm{g} \mathrm{kg}^{-1}\right)$ at $800 \mathrm{~m}$ from the WOA13 climatology during 2005 to 2012. (i.e. WOA0512 in Fig. 23). Panel (b) shows the difference with the entire time span of the data set provided, i.e. WOA0512 minus WG_all. The grey contour shows the $2000 \mathrm{~m}$ isobath.

in a detailed manner. While all climatologies provide maps on standardized depth levels (and neutral density surfaces in WOCE), the WG data sets also provide maps of the level of the sub-surface temperature maximum. This is the level representing the core of incoming source water. While fields of potential temperature and practical salinity are provided, gridded fields of conservative temperature and absolute salinity are also provided; conservative temperature is deemed more representative of the "heat content" of seawater than potential temperature (McDougall and Barker, 2011).

Figure 24 shows (a) the conservative temperature at $800 \mathrm{~m}$ from WOA13 (time span 2005 to 2012; Locarnini et al., 2013) and (b) the corresponding difference between WOA13 and WG_all. Figure 25 shows the same for absolute salinity (Zweng et al., 2013), and Figs. 26 and 27 are the same as Figs. 24 and 25 but using the WOCE_global atlas (19002000; Gouretski and Koltermann, 2004). Note that temperature and salinity from WOA13 and WOCE_global are used to calculate conservative temperature and absolute salinity, WG_all is on a pressure surface of $800 \mathrm{dbar}$, and the WG grid had to be interpolated to match the WOA13 grid for this rough comparison. WOA13 is considerably smoother than WG_all (Figs. 21 and 22). In particular, the Taylor column over Maud Rise as discussed in Sect. 5 is not visible nor is the warm and salty tongue that emerges to the south and west
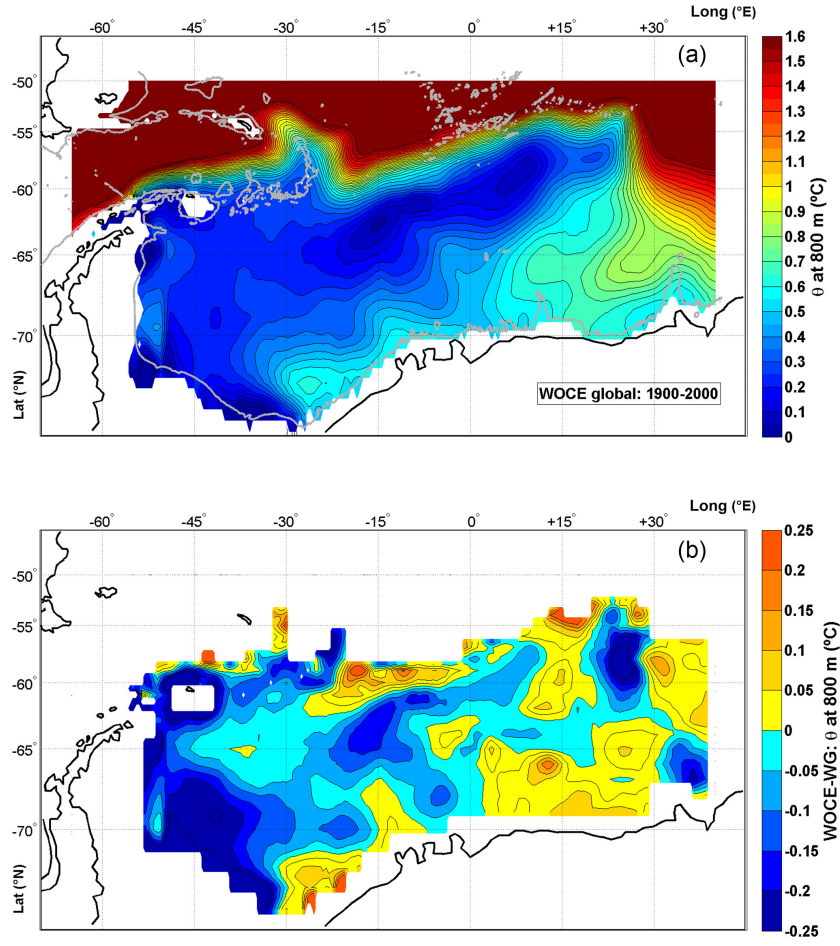

Figure 26. Conservative temperature $\left({ }^{\circ} \mathrm{C}\right)$ at $800 \mathrm{~m}$ from the global WOCE climatology during 1900 to 2000. (i.e. WOCE_global in Fig. 23). Panel (b) shows the difference with the entire time span of the data set provided, i.e. WOCE_global minus WG_all. The grey contour shows the $2000 \mathrm{~m}$ isobath.

of Maud Rise, half way between Maud Rise and the coast, that appears to be curving around Maud Rise. This warm and salty tongue of water is a small feature and yet it is present in the longer-time-period composite of WOCE in Fig. 26, although the Taylor column is not. This may be because the WOA13 is from the $1^{\circ} \times 1^{\circ}$ grid, whereas the WOCE grid is a $\frac{1}{4}^{\circ} \times \frac{1}{4}^{\circ}$ grid; however, the WG grid succeeds in representing these features, possibly a result of incorporating the cross-isobath separation component into the decay scale, which is discussed above. A potential reason why WOA13 omits the smaller-scale details is that the mapped fields were also smoothed with a median filter and a five-point smoother (Locarcini et al., 2013). The far south along the $2000 \mathrm{~m}$ contour between 15 and $45^{\circ} \mathrm{W}$ is unique across all three maps. WOCE displays this region as a particularly cold and fresh stretch parallel to the $2000 \mathrm{~m}$ isobaths. WOA13 displays an alternation between cold and fresh and warm and salty water, which extends northwards from the $2000 \mathrm{~m}$ isobath. This region is marked as an area of relatively large mapping error (in excess of $0.05^{\circ} \mathrm{C}$ and $0.005 \mathrm{~g} \mathrm{~kg}^{-1}$ for temperature and salinity in Figs. 21 and 22, i.e. at the upper range of error for the region), and therefore caution should be exercised in interpreting the results in this area. The maps show a slightly warmer region in comparison to the region just north 

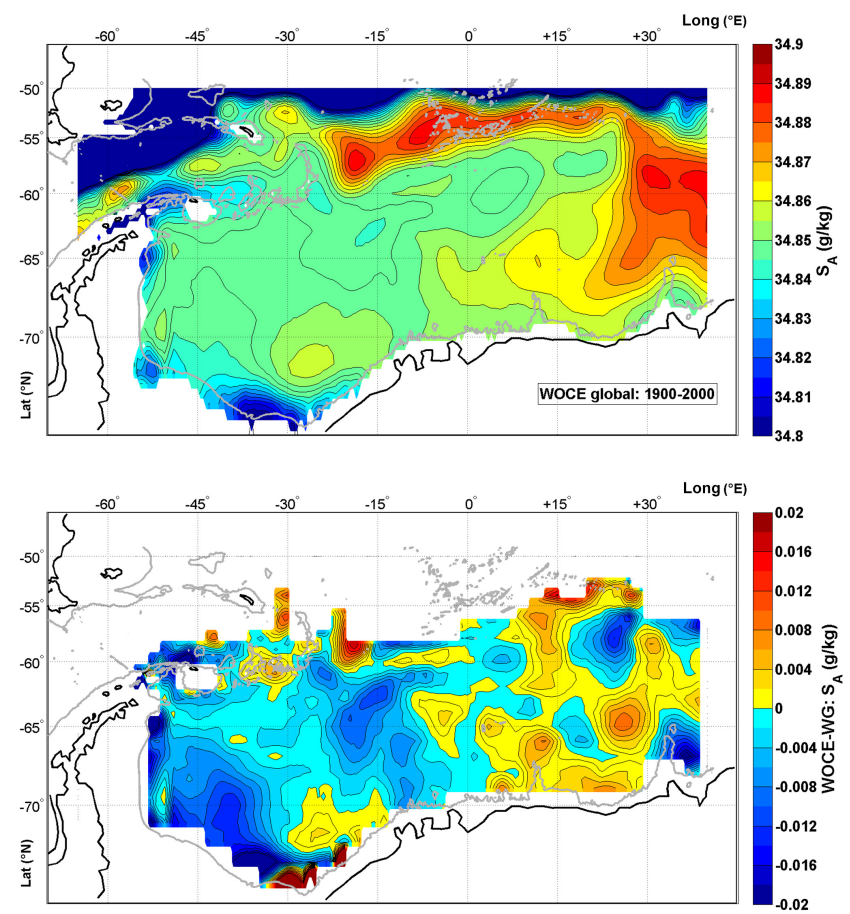

Figure 27. Absolute salinity $\left(\mathrm{g} \mathrm{kg}^{-1}\right)$ at $800 \mathrm{~m}$ from the global WOCE climatology during 2005 to 2012. (i.e. WOCE_global in Fig. 23). Panel (b) shows the difference with the entire time span of the data set provided, i.e. WOCE_global minus WG_all. The grey contour shows the $2000 \mathrm{~m}$ isobath.

(of about $72^{\circ} \mathrm{S}$ ). The difference between WOA13 and WG is relatively small in general (less than $0.05^{\circ} \mathrm{C}$ and for temperature and 0.004 for salinity; Figs. 24b and 25b), which increases in regions where the WG map shows more complex features. In general the WOA map appears to show slightly warmer and saltier values than the WG map (i.e. more blue than yellow or orange), although roughly $30-40 \%$ is slightly cooler and fresher. The WOCE maps shows greater differences in general, as the majority of the gyre interior is warmer and saltier (Figs. 26b and 27b). There appears to be a zonal pattern in the differences, in that for about $80 \%$ of the region west of $0^{\circ} \mathrm{E}$, WOCE is warmer than WG_all, and for about $60-70 \%$ of the region west of $0^{\circ} \mathrm{E}$, it is cooler. This zonal pattern is even stronger in salinity. The main question is whether these differences are the result of methodical differences (such as data source and interpolation methods) or the result of representing different time periods and thus indicative of long-term change.

\subsection{Water mass properties of the Weddell Gyre along the Prime Meridian}

In order to assess the resulting water mass properties of the WG data sets, a section of the Prime Meridian is presented. This is because a large proportion of literature focusing on long-term change in the Weddell Gyre focuses on this region
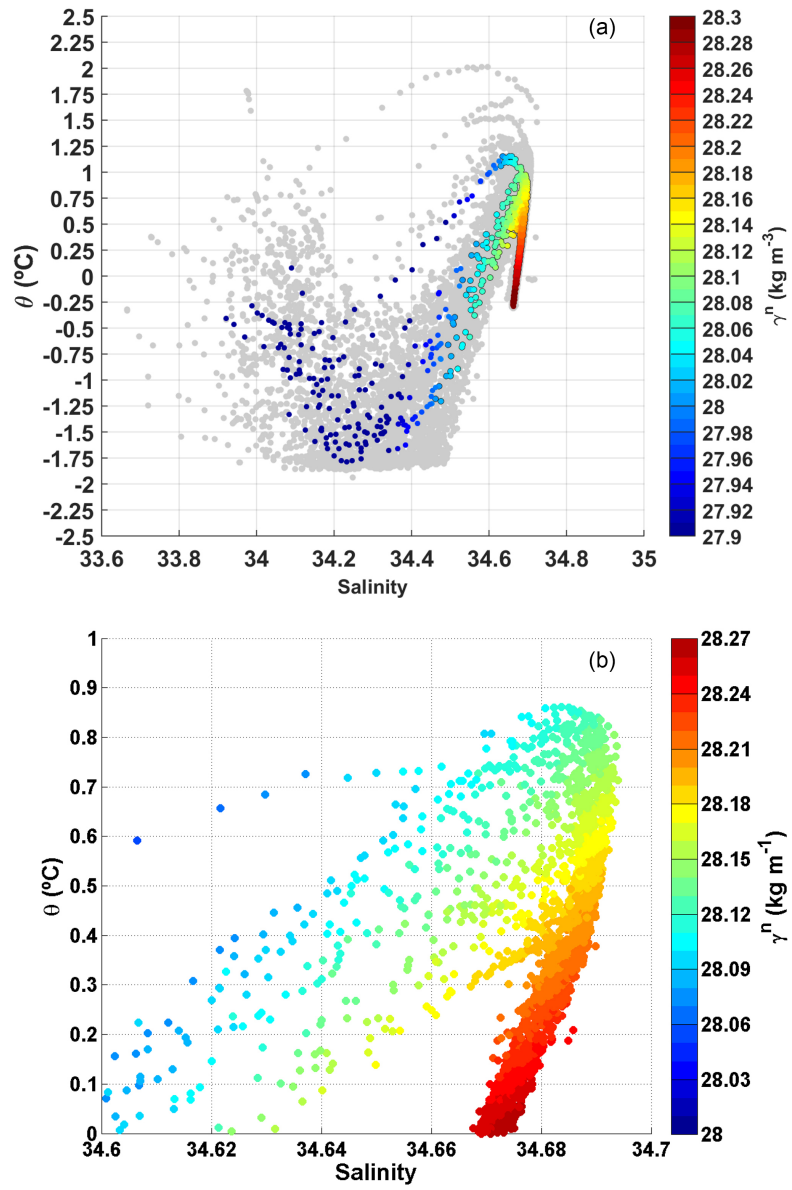

Figure 28. Potential-temperature $\left({ }^{\circ} \mathrm{C}\right)$-salinity diagram of (a) data extracted from the entire time span data set (WG_all) from along the Prime Meridian. The colour bar shows the corresponding neutral density $\left(\mathrm{kg} \mathrm{m}^{-3}\right)$. The original float profile data extracted from within $1.5^{\circ}$ of the Prime Meridian are shown in the background in grey. Panel (b) shows the potential-temperature $\left({ }^{\circ} \mathrm{C}\right)$-salinity diagram of gridded data extracted from the entire time period (WG_all) from a region south of $60^{\circ} \mathrm{S}$ between 10 and $25^{\circ} \mathrm{W}$. The axis limits match the boundary definitions of WDW, and the colour bar shows neutral density, for direct comparison of WDW with Fig. 4b in Heywood and King (2002).

due to data availability (see, e.g., Fahrbach et al., 2011). As there are no grid cell centres falling directly onto the Prime Meridian, in order to create the sections in Figs. 29 to 31, the mean of the two nearest grid cells (the immediate grid cells to the east and west of the Prime Meridian) is created for each variable. Note that the following figures show potential temperature and practical salinity for the purpose of comparison to the literature. Figure 28a shows a $T-S$ diagram for all grid cells along the Prime Meridian, where the colour indicates the corresponding neutral density. All original Argo float profiles within $1.5^{\circ}$ of $0^{\circ} \mathrm{E}$ are shown in the background in grey. The sub-surface temperature maximum is shown mostly at about $1{ }^{\circ} \mathrm{C}$, although the two northernmost grid cells show a 

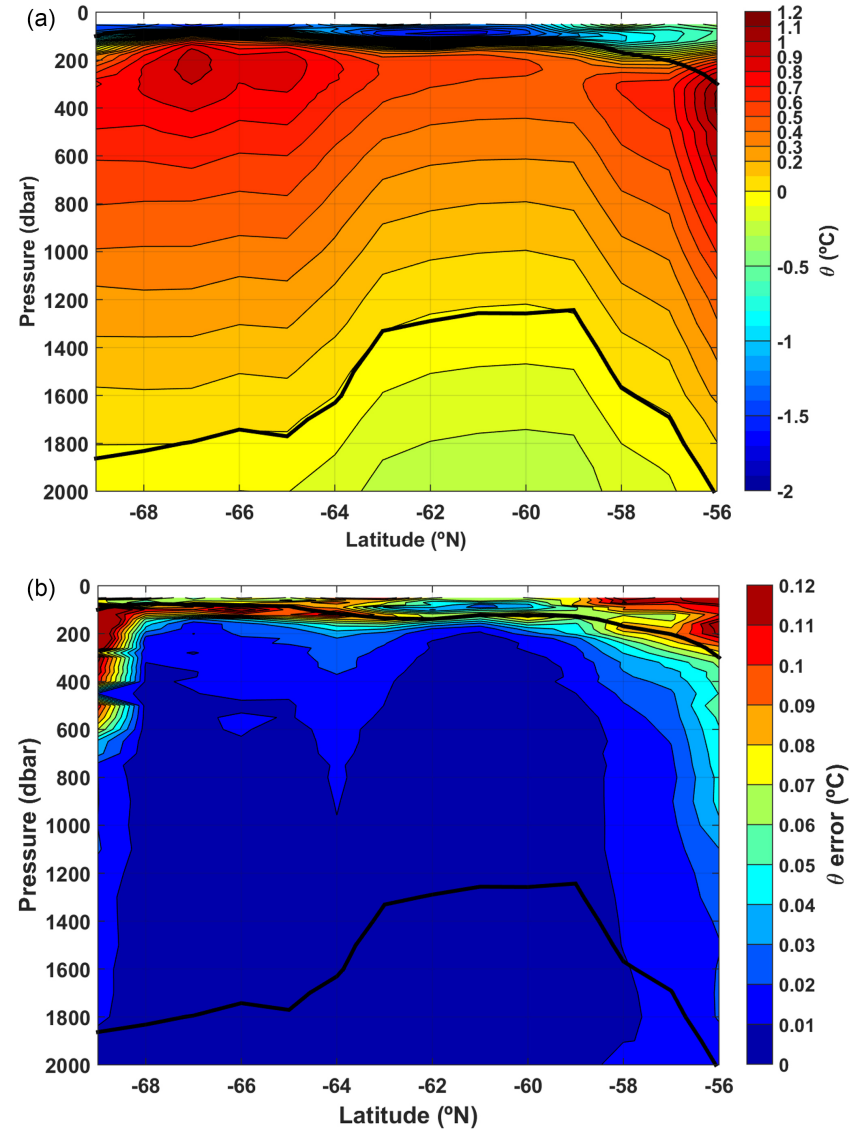

Figure 29. Potential temperature $\left({ }^{\circ} \mathrm{C}\right)$ (a) and mapping error $\left({ }^{\circ} \mathrm{C}\right)$ (b) for a section from $56^{\circ} \mathrm{S}$ to the coast along the Prime Meridian. The sections consist of the mean of the two grid cell sections adjacent to $0^{\circ} \mathrm{E}$. The thick black lines show the upper and lower boundaries of WDW, i.e. the neutral densities of 28.0 and $28.27 \mathrm{~kg} \mathrm{~m}^{-3}$ respectively.

Tmax of about 1.1 to $1.2^{\circ} \mathrm{C}$. The surface values spread out considerably and are colder and fresher than the underlying water column. Argo floats are ideally suited to investigating WDW properties as WDW is fully encompassed within the top $2000 \mathrm{~m}$, the depth limit of Argo floats. This is illustrated in Fig. 28, which captures the full range of WDW. WDW is characterized having a potential temperature of more than $0{ }^{\circ} \mathrm{C}$ and salinity of more than 34.6 (Carmack and Foster, 1975 ) or, taking a more conservative approach, neutral density limits of 28 to $28.27 \mathrm{~kg} \mathrm{~m}^{-3}$ (Fahrbach et al., 2011). Figure 28a shows good general agreement with the $T-S$ diagram of Fig. 2 in Schroeder and Fahrbach (1999), which comprises data from six hydrographic surveys, in which most stations are located on the Prime Meridian (note that these stations record information on the entire water column from the surface to the sea floor). Figure $28 b$, which focuses on WDW within a sample region south of $60^{\circ} \mathrm{S}$ and between 25 and $10^{\circ} \mathrm{W}$, agrees well with Fig. $4 \mathrm{~b}$ in Heywood and
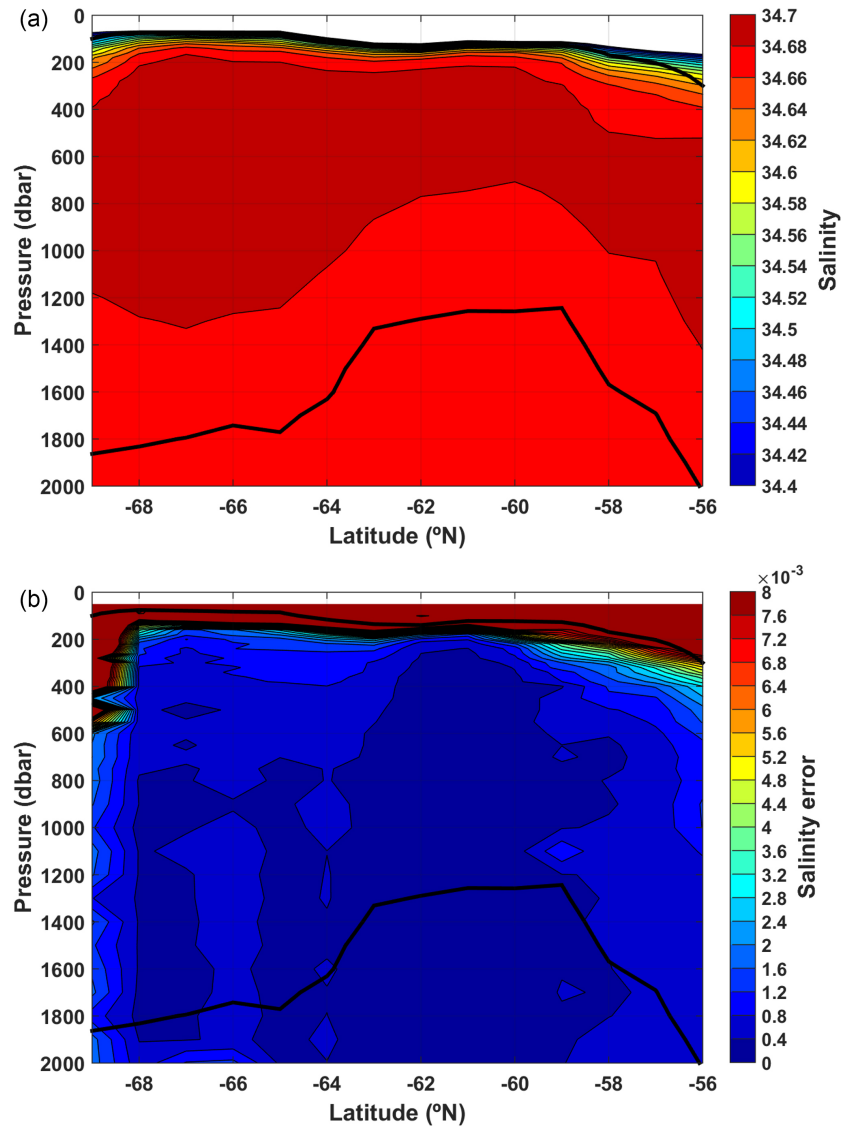

Figure 30. Salinity (a) and mapping error (b) for a section from $56^{\circ} \mathrm{S}$ to the coast along the Prime Meridian. The sections consist of the mean of the two grid cell sections adjacent to $0^{\circ} \mathrm{E}$. The thick black lines show the upper and lower boundaries of WDW, i.e. the neutral densities of 28.0 and $28.27 \mathrm{~kg} \mathrm{~m}^{-3}$ respectively.

King (2002), which focuses on WDW in the Weddell Gyre at about $20^{\circ} \mathrm{E}$.

Figures 29, 30 and 31 show the cross section along the Prime Meridian of (a) potential temperature, salinity and neutral density respectively along with the corresponding mapping errors (b). Similar figures can be found in Fahrbach et al. (2011) for potential temperature and neutral density from 1992 (Fig. 4a, b) and 2008 (Fig. 4c, d) and in Klatt et al. (2005) for mean potential temperature and mean salinity for the period 1992 to 2000 (Fig. 4). Note the depth range differences and the direction from north to south along the $x$ axis. In particular, the domed structure of the gyre can be seen, with the contours shoaling towards the centre and with the central axis at about $61^{\circ} \mathrm{S}$. The incoming Lower Circumpolar Deep Water can be identified as a temperature maximum of about $1.1-1.2^{\circ} \mathrm{C}$ in Fig. 29 at about $67^{\circ} \mathrm{S}$, with its core at about $200 \mathrm{~m}$, in agreement with Fahrbach et al. (2011) and Klatt et al. (2005), although in the latter, the Tmax is further south at about $68.5^{\circ} \mathrm{S}$. Across all three sources, the deeper $0{ }^{\circ} \mathrm{C}$ contour, which generally agrees with 

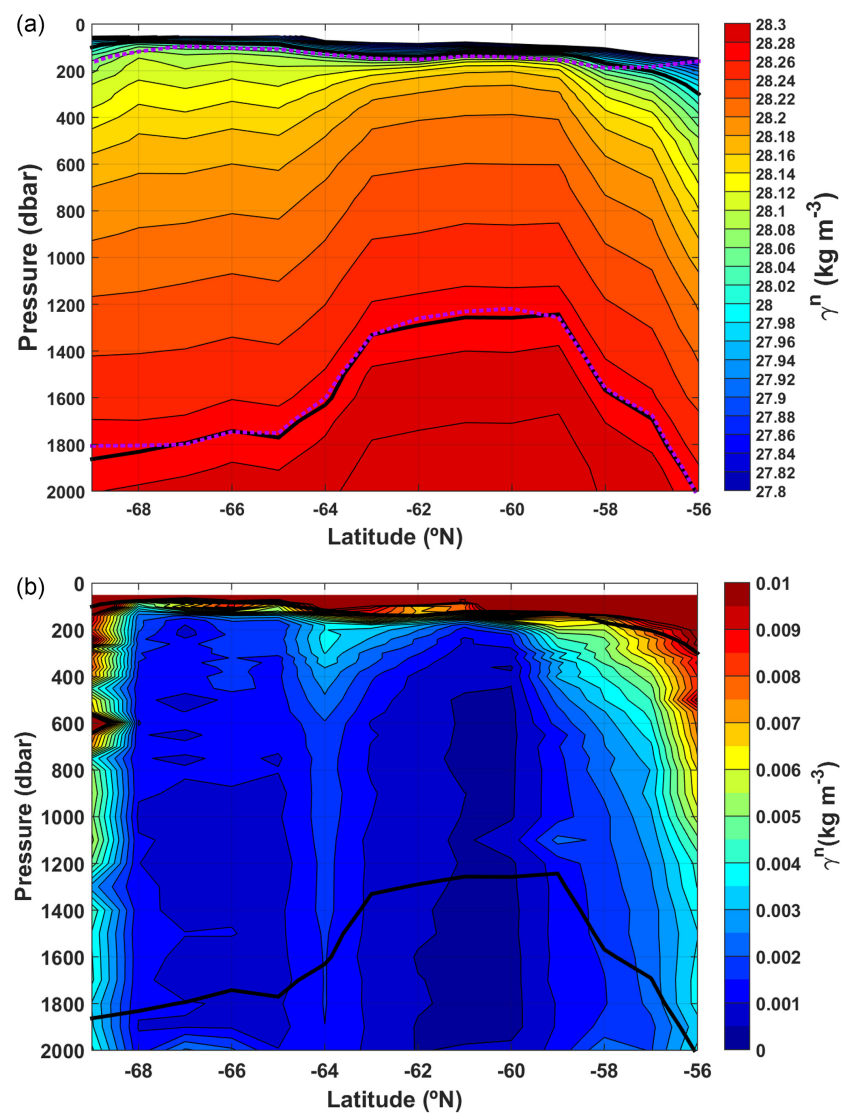

Figure 31. Neutral density $\left(\mathrm{kg} \mathrm{m}^{-3}\right)$ (a) and mapping error $\left(\mathrm{kg} \mathrm{m}^{-3}\right)$ (b) for a section from $56^{\circ} \mathrm{S}$ to the coast along the Prime Meridian. The sections consist of the mean of the two grid cell sections adjacent to $0^{\circ} \mathrm{E}$. The dashed magenta (and panel $\mathbf{b}$ : solid black) lines show the upper and lower boundaries of WDW, i.e. the neutral densities of 28.0 and $28.27 \mathrm{~kg} \mathrm{~m}^{-3}$ respectively. The dashed magenta line in panel (a) shows the $0{ }^{\circ} \mathrm{C}$ contour; another definition of the WDW boundaries.

the $28.27 \mathrm{~kg} \mathrm{~m}^{-3} \gamma^{n}$ contour (i.e. the deep WDW boundary definition; shown as the thick black contour in Figs. 29-31a), is in agreement. At its shallowest, the deep WDW boundary occurs at about $1200 \mathrm{~m}$ at $\sim 60^{\circ} \mathrm{S}$ (in Fahrbach et al., 2011 , this occurs slightly to either side of $60^{\circ} \mathrm{S}$ for the 1992 cruise) and deepens slightly to about $1300 \mathrm{~m}$ at $63^{\circ} \mathrm{S}$, before deepening at a steeper gradient to about $1750 \mathrm{~m}$ at 64 $5^{\circ} \mathrm{S}$. Klatt et al. (2005) show agreement with Fig. 30, where the salinity contour of more than 36.68 "bulges out" south of about $63^{\circ} \mathrm{S}$, from a minimum at $59-60^{\circ} \mathrm{S}(\sim 700 \mathrm{~m})$ to a maximum at $67^{\circ} \mathrm{S}(\sim 1300 \mathrm{~m})$. The bulge coincides with the core of incoming Circumpolar Deep Water previously discussed. The general similarities are remarkable considering the different sources and time periods (the literature uses CTD data from research vessel expeditions), although the features highlighted do not allow comparison of the shallow regions, where the corresponding mapping errors are largest (especially north of the upper boundary of WDW marked by
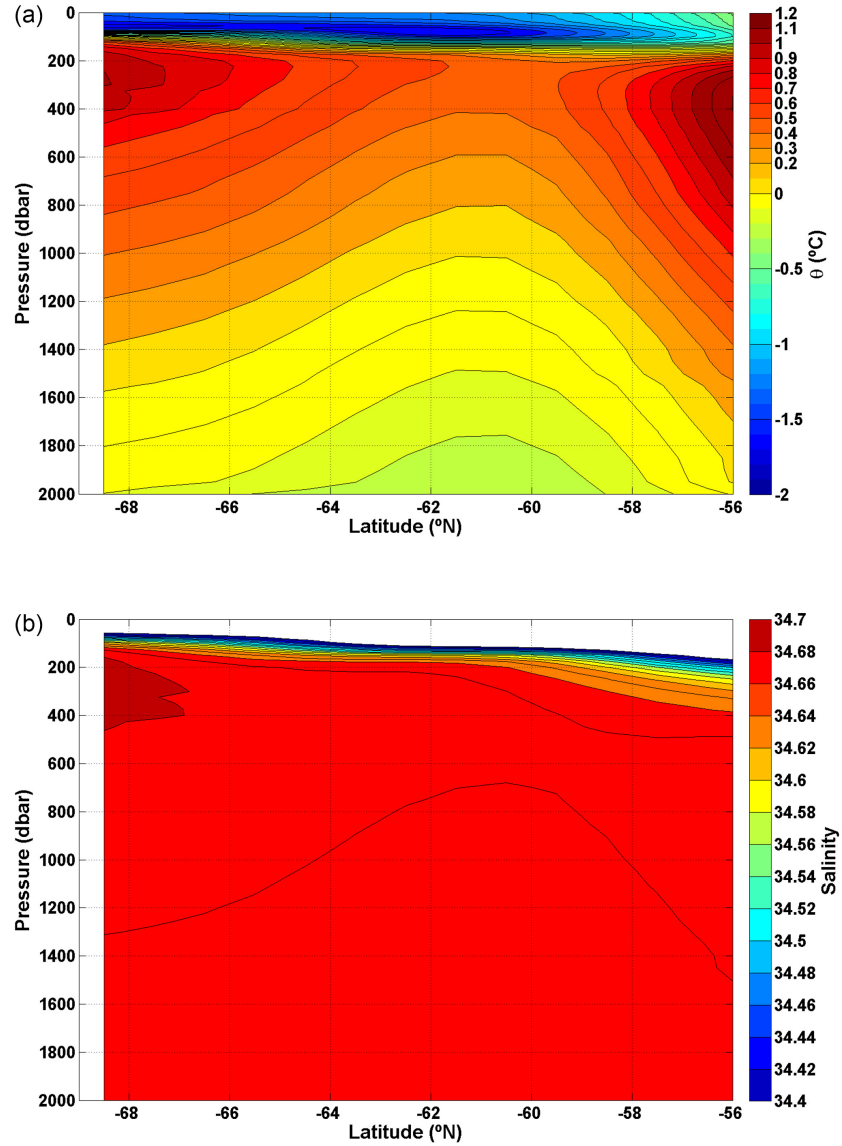

Figure 32. Potential temperature $\left({ }^{\circ} \mathrm{C}\right)$ (a) and salinity (b) for a section from $56^{\circ} \mathrm{S}$ to the coast along the Prime Meridian from the WOA13 climatology; time span 2005 to 2012.

the thick black contour in Figs. 29 to $31 ; 28.0 \mathrm{~kg} \mathrm{~m}^{-3} \gamma^{n}$ ). Figure 32 shows potential temperature and salinity extracted from WOA13 (2005 to 2012). The gradients of the contours are considerably smoother than both in the literature and the sections in Figs. 29 and 30 ; the $0^{\circ} \mathrm{C}$ contour is shallowest at $61^{\circ} \mathrm{S}$ at $800 \mathrm{~m}$ in Fig. 32a (in comparison to $1200 \mathrm{~m}$ in Fig. 29a). There is no discernable steepening of the meridional gradient between $63^{\circ}$ and $64-65^{\circ} \mathrm{S}$, and the contour is about $1300 \mathrm{~m}$ at $65^{\circ} \mathrm{S}$ (in comparison to $\sim 1750 \mathrm{~m}$ of the mapped data in Fig. 29a).

The WG data sets generally perform well in the context of current literature on the Weddell Gyre water mass properties. The main way in which the new data sets provided could be further improved is the inclusion of additional data. As more data become available, it may be possible to reduce the length scales used and to incorporate a temporal separation component into the second-pass decay scale, both of which would lead to resolving the gridded fields to smaller scales (both spatially and temporally). Another key improvement (and indeed priority in the field of Argo floats) of any future gridded data sets is the improvement of the position 
estimates of under-ice floats (see Sect. 2). However, the aim is to provide an Argo-only data set, of relatively small time spans, looking at the large-scale mean field. In general, the resulting gridded hydrographic fields show good agreement with other climatologies and current knowledge of the water masses drawn from ship data. The main question that remains is whether the differences noted, in particular between climatologies and the data set presented in this paper, are the result of methodology or are suggestive of changes in the Weddell Sea climatic system.

\section{Concluding remarks}

The objective of this paper was to provide a spatially gridded data set of the upper $2000 \mathrm{~m}$ of the water column properties of the entire Weddell Gyre region. Objective mapping was applied in a two-step process to Argo float profile data spanning December 2001 to March 2013 and to subsets of the float data for the 2002-2005, 2006-2009 and 2010-March 2013 periods. Maps of pressure, conservative temperature and absolute salinity are provided at the level of the sub-surface temperature maximum, and maps of conservative temperature and absolute salinity are provided at 41 standardized pressure levels ranging from 50 to $2000 \mathrm{dbar}$ (along with additional fields of potential temperature and practical salinity). The corresponding mapping errors are also provided. The resulting mapped fields provide a complete, detailed view of the large-scale pertinent features of the Weddell Gyre, such as the doming of the gyre centre owing to its cyclonic rotation and the associated relatively cool gyre interior. The relatively warm incoming source wa- ter at the eastern sector of the southern limb is also visible, although considerable data gaps in this region require caution when interpreting the data, along with the variability of water properties owing to bathymetric features such as Maud Rise, which is not clearly visible in the climatologies investigated in Sect. 6.1. The mapping errors corresponding to the mapped field variables are relatively small, with the exception of regions where the bathymetry is complex or where data coverage is limited. The mapping errors vary with pressure, where the overall largest mapping errors coincide with the layer of the Winter Water, particularly within the vicinity of its lower boundary (about 120-180 dbar). In order to gauge the performance of the mapping procedure, objective mapping was also applied to the location of the float profiles themselves. The objective mapping successfully represents the Weddell Gyre in its entirety, whereby $89 \%$ of mapped profiles within the Weddell Gyre differ from the original profile values (for temperature at $800 \mathrm{dbar}$ ) by less than $0.2^{\circ} \mathrm{C}$. Comparison of the gridded fields of data with both climatologies and the literature show good agreement, which also suggests that the mapping procedure has been successful in representing Weddell Gyre hydrography. Caution should be exercised when considering the increased mapping error at the gyre periphery, in regions of limited data coverage, and due to the fact that all mapped fields are spatially gridded temporal composites. The work presented here provides the prerequisite technical component of investigations into the variability of Weddell Gyre water mass properties, providing further insight into the role of the Weddell Gyre in a changing climate. 
Appendix A: Data format: gridded fields of upper Weddell Gyre water properties

The time-composite data sets of mapped field variables are provided as netCDF files, with one file for each available time period. The filenames and corresponding variables provided in each netCDF file are listed in Tables A1 and A2 respectively. Mapped fields of conservative temperature $\left({ }^{\circ} \mathrm{C}\right)$, absolute salinity $\left(\mathrm{g} \mathrm{kg}^{-1}\right)$, potential temperature, practical salinity and potential density $\left(\mathrm{kg} \mathrm{m}^{-3}\right)$ as well as corresponding mapping errors are provided for 41 vertical pressure levels (listed in Table 1). Additionally, conservative temperature, absolute salinity and pressure (dbar) at the level of the subsurface temperature maximum are provided. The coordinates represent the centre of each grid cell. The missing value is defined by NaN. Further details found in the global attributes of the netCDF files are described throughout the main paper.
Table A1. List of netCDF filenames where the mapped field variables for the different time-composite periods are found.

\begin{tabular}{l}
\hline Name of netCDF files \\
\hline WeddellGyre_OM_Period2001 to2013.nc \\
WeddellGyre_OM_Period2001 to2005.nc \\
WeddellGyre_OM_Period2006to2009.nc \\
WeddellGyre_OM_Period2010to2013.nc \\
WeddellGyre_OM_Period2001 to2014_potTpSal.nc \\
WeddellGyre_OM_Period2001 to2005_potTpSal.nc \\
WeddellGyre_OM_Period2006to2009_potTpSal.nc \\
WeddellGyre_OM_Period2010to2014_potTpSal.nc
\end{tabular}


Table A2. List of variable names in the accompanying netCDF file. The mapped variables listed are provided in the form of grids structured by latitude $\times$ longitude $\times$ pressure level, where fill values are NaNs. The asterisk $(*)$ indicates variables which are not found in the netCdf file of the entire 11-year time period, WeddellGyre_OM_Period2001to2013.nc.

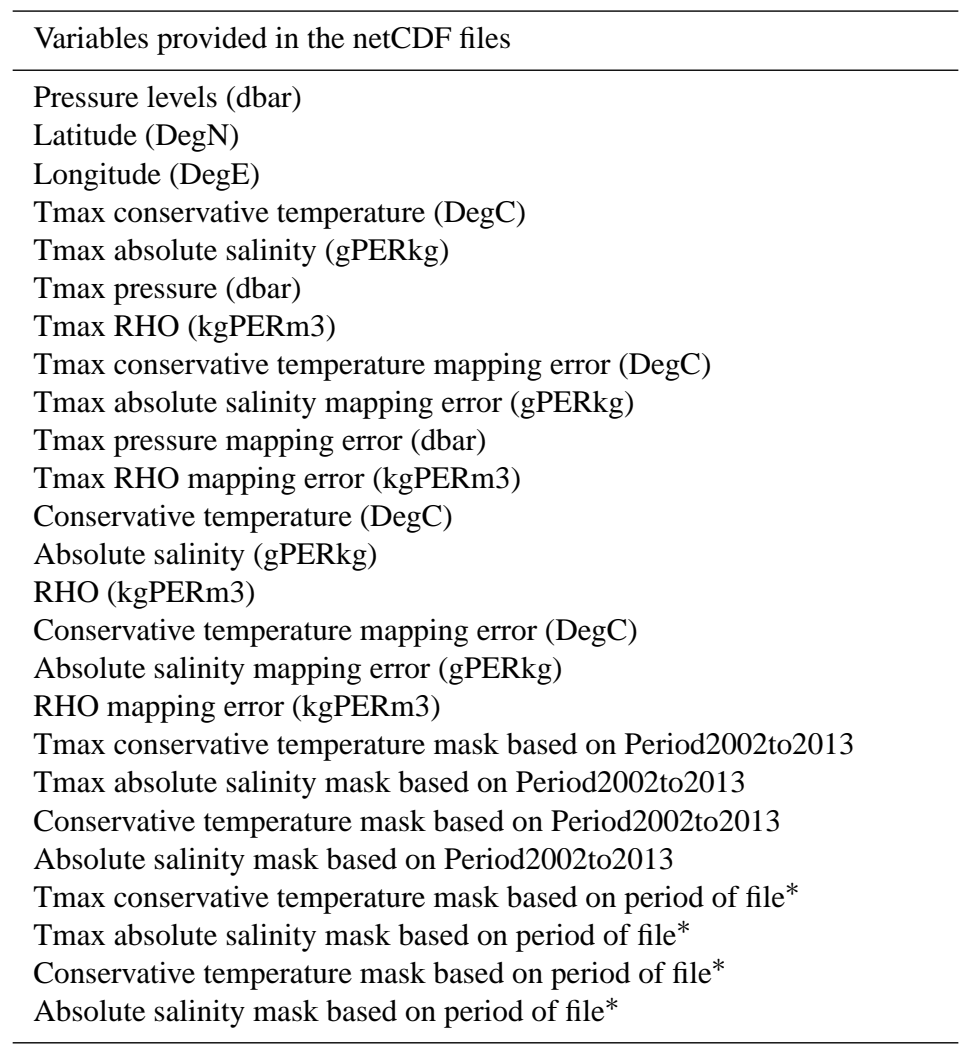


Acknowledgements. These data were collected and made freely available by the International Argo Program and the national programs that contribute to it (http://www.argo.ucsd.edu, http://argo.jcommops.org). The Argo Program is part of the Global Ocean Observing System. The GEBCO Digital Atlas is published by the British Oceanographic Data Centre on behalf of IOC and IHO, 2003. This work is dedicated to the memory of Eberhard Fahrbach (who passed away on 21 April 2013), a great Polar Oceanographer who championed the observation of the Polar Oceans and was an inspiration to us all. The authors would like to thank the anonymous reviewers for their invaluable feedback.

Edited by: D. Carlson

\section{References}

Antonov, J. I., Locarnini, R. A., Boyer, T. P., Mishonov, A. V., and Garcia, H. E.: World Ocean Atlas 2005, Volume 2: Salinity, edited by: Levitus, S., NOAA Atlas NESDIS 62, U.S. Government Printing Office, Washington, D.C., USA, 182 pp., 2006.

Antonov, J. I., Seidov, D., Boyer, T. P., Locarnini, R. A., Mishonov, A. V., Garcia, H. E., Baranova, O. K., Zweng, M. M., and Johnson, D. R.: World Ocean Atlas 2009, Volume 2: Salinity, edited by: Levitus, S., NOAA Atlas NESDIS 69, U.S. Government Printing Office, Washington, D.C., USA, 184 pp., 2010.

Barnes, S. L.: A technique for maximizing details in numerical weather map analysis, J. Appl. Meteorol., 3, 396-409, 1964.

Barnes, S. L.: Applications of the Barnes Objective Analysis Scheme, Part III: Tuning for Minimum Error, J. Atmos. Ocean. Tech., 11, 1459-1479, 1994.

Beckmann, A., Hellmer, H. H., and Timmermann, R.: A numerical model of the Weddell Sea: large-scale circulation and water mass distribution, J. Geophys. Res., 104, 23375-23391, 1999.

Behrendt, A., Fahrbach, E., Hoppema, M., Rohardt, G., Boebel, O., Klatt, O., Wisotzki, A., and Witte, H.: Variations of winter water properties and sea ice along the greenwich meridian on decadal time scales, Deep-Sea Res. Pt. II, 58, 2524-2532, doi:10.1016/j.dsr2.2011.07.001, 2011.

Bersch, M., Becker, G. A., Frey, H., and Koltermann, K. P.: Topographic effects of the Maud Rise on the stratification and circulation of the Weddell Gyre, Deep-Sea Res., 39, 303-331, 1992.

Böhme, L. and Send, U.: Objective analyses of hydrographic data for referencing profiling float salinities in highly variable environments, Deep-Sea Res. Pt. II, 52, 651-664, doi:10.1016/j.dsr2.2004.12.014, 2005.

Brennecke, W.: Ozeanographische Ergebnisse der zweiten französischen, der schwedischen und der schottischen Südpolarexpedition, Annalen der Hydrographie und Maritimen Meteorologie, 46, 173-183, 1918.

Bretherton, F. P., Davis, R. E., and Fandry, C. B.: A technique for objective analysis and design of oceanographic experiments applied to mode-73, Deep-Sea Research and Oceanographic Abstracts, 23, 559-582, doi:10.1016/0011-7471(76)90001-2, 1976.

Carmack, E. and Foster, T.: On the flow of water out of the Weddell Sea, Deep-Sea Res., 22, 711-724, 1975.

Chang, Y.-S., Rosati, A. J., Zhang, S., and Harrison, M. J.: Objective analysis of monthly temperature and salinity for the world ocean in the 21st century: Comparison with world ocean atlas and ap- plication to assimilation validation, J. Geophys. Res.-Oceans, 114, C02014, doi:10.1029/2008jc004970, 2009.

Cisewski, B., Strass, V., and Leach, H.: Circulation and transport of water masses in the Lazarev Sea, Antarctica, during summer and winter 2006, Deep-Sea Res. Pt. I, 58, 186-199, doi:10.1016/j.dsr.2010.12.001, 2011.

Cressman, G. P.: An operational objective analysis scheme, Mon. Weather Rev., 87, 329-340, 1959.

Deacon, G. E. R.: The Weddell Gyre, Deep-Sea Res., 26A, 981995, 1979.

Fahrbach, E. and de Baar, H.: The expedition of the research vessel "polarstern" to the antarctic in 2008 (ant-xxiv/3). Polar- und Meeresforschung 606, AWI, Bremerhaven, Germany, 228 pp., doi:10013/epic.34050, 2010.

Fahrbach, E., Rohardt, G., Schröder, M., and Strass, V.: Transport and structure of the Weddell Gyre, Ann. Geophys., 12, 840-855, doi:10.1007/s00585-994-0840-7, 1994.

Fahrbach, E., Rohardt, G., Scheele, N., Schröder, M., Strass, V., and Wisotzki, A.: Formation and discharge of deep and bottom water in the northwestern Weddell Sea, J. Mar. Res., 53, 515538, 1995.

Fahrbach, E., Hoppema, M., Rohardt, G., Schröder, M., and Wisotzki, A.: Decadal-scale variations of water mass properties in the deep weddell sea, Ocean Dynam., 54, 77-91, doi:10.1007/s10236-003-0082-3, 2004.

Fahrbach, E., Rohardt, G., and Sieger, R.: 25 years of polarstern hydrography (1982-2007), WDC-MARE Reports 5, AlfredWegener-Institut, Bremerhaven, Germany, 94 pp., 2007.

Fahrbach, E., Hoppema, M., Rohardt, G., Boebel, O., Klatt, O., and Wisotzki, A.: Warming of deep and abyssal water masses along the greenwich meridian on decadal time scales: The weddell gyre as a heat buffer, Deep-Sea Res. Pt. II, 58, 2509-2523, doi:10.1016/j.dsr2.2011.06.007, 2011.

Foster, T. D., Foldvik, A., and Middleton, J. H.: Mixing and bottom water formation in the shelf break region of the southern weddell sea, Deep-Sea Res., 34, 1771-1794, doi:10.1016/01980149(87)90053-7, 1987.

Gandin, L. S.: Objective analysis of meteorological fields, Israel Program for Scientific Translations, Jerusalem, Israel, 1965.

Gouretski, V. V. and Koltermann, K. P.: WOCE Global Hydrographic Climatology. 35/2004, Berichte des Bundesamtes fur Seeschifffahrt und Hydrographie, Hamburg, Rostock, Germany, 52 pp., 2004.

Hadfield, R. E., Wells, N. C., Josey, S. A., and Hirschi, J. J. M.: On the accuracy of north atlantic temperature and heat storage fields from argo, J. Geophys. Res.-Oceans, 112, C01009, doi:10.1029/2006jc003825, 2007.

Heywood, K. J. and King, B. A.: Water masses and baroclinic transports in the South Atlantic and Southern Oceans, J. Marine Res., 60, 5, 639-676, 2002.

IOC, IHO, and BODC: Centenary edition of the gebco digital atlas, in: Published on CD-ROM on behalf of the Intergovernmental Oceanographic Commission and the International Hydrographic Organization as part of the General Bathymetric Chart of the Oceans, British Oceanographic Data Centre, Liverpool, UK, 2003.

IOC, SCOR, and IAPSO: The international thermodynamic equation of seawater - 2010: Calculation and use of thermodynamic properties. Intergovernmental Oceanographic Commis- 
sion, Manuals and Guides No. 56, UNESCO, Paris (English), France, 196 pp., 2010.

Johnson, G. C.: Quantifying antarctic bottom water and north atlantic deep water volumes, J. Geophys. Res.-Oceans, 113, C05027, doi:10.1029/2007jc004477, 2008.

Klatt, O., Fahrbach, E., Hoppema, M., and Rohardt, G.: The transport of the weddell gyre across the prime meridian, Deep-Sea Res. Pt. II, 52, 513-528, doi:10.1016/j.dsr2.2004.12.015, 2005.

Klatt, O., Boebel, O., and Fahrbach, E.: A profiling float's sense of ice, J. Atmos. Ocean. Tech., 24, 1301-1308, doi:10.1175/jtech2026.1, 2007.

Leach, H., Strass, V., and Cisewski, B.: Modification by Lateral Mixing of the Warm Deep Water entering the Weddell Sea in the Maud Rise Region, Ocean Dynam., 61, 51-68, doi:10.1007/s10236-010-0342-y, 2011.

Levitus, S., Antonov, J. I., Boyer, T. P., Baranova, O. K., Garcia, H. E., Locarnini, R. A., Mishonov, A. V., Reagan, J. R., Seidov, D., Yarosh, E. S., and Zweng, M. M.: World ocean heat content and thermosteric sea level change (0-2000 m), 1955-2010, Geophys. Res. Lett., 39, L10603, doi:10.1029/2012g1051106, 2012.

Locarnini, R. A., Mishonov, A. V., Antonov, J. I., Boyer, T. P., and Garcia, H. E.: World Ocean Atlas 2005, Volume 1: Temperature, edited by: Levitus, S., NOAA Atlas NESDIS 61, U.S. Government Printing Office, Washington, D.C., USA, 182 pp., 2006.

Locarnini, R. A., Mishonov, A. V., Antonov, J. I., Boyer, T. P., Garcia, H. E., Baranova, O. K., Zweng, M. M., and Johnson, D. R.: World Ocean Atlas 2009, Volume 1: Temperature, edited by: Levitus, S., NOAA Atlas NESDIS 68, U.S. Government Printing Office, Washington, D.C., USA, 184 pp., 2010.

Locarnini, R. A., Mishonov, A. V., Antonov, J. I., Boyer, T. P., Garcia, H. E., Baranova, O. K., Zweng, M. M., Paver, C. R., Reagan, J. R., Johnson, D. R., Hamilton, M., and Seidov, D.: World Ocean Atlas 2013, Volume 1: Temperature, edited by: Levitus, S. and Mishonov, A., NOAA Atlas NESDIS 73, Silver Spring, MD, USA, 40 pp., 2013.

Lyman, J. M. and Johnson, G. C.: Estimating annual global upperocean heat content anomalies despite irregular in situ ocean sampling, J. Climate, 21, 5629-5641, doi:10.1175/2008jcli2259.1, 2008.

Lyman, J. M., Good, S. A., Gouretski, V. V., Ishii, M., Johnson, G. C., Palmer, M. D., Smith, D. M., and Willis, J. K.: Robust warming of the global upper ocean, Nature, 465, 334-337, doi:10.1038/nature09043, 2010.

McDougall T. J. and Barker, P. M.: Getting started with TEOS-10 and the Gibbs Seawater (GSW) Oceanographic Toolbox, 28 pp., SCOR/IAPSO WG127, ISBN 978-0-646-55621-5, 2011.
McIntosh, P. C.: Oceanographic data interpolation: Objective analysis and splines, J. Geophys. Res.-Oceans, 95, 13529-13541, doi:10.1029/JC095iC08p13529, 1990.

Muench, R. D., Morison, J. H., Padman, L., Martinson, D., Schlosser, P., Huber, B., and Hohmann, R.: Maud Rise revisited, J. Geophys. Res., 106, 2423-2440, 2001.

Orsi, A. H. and Whitworth III., T.: Hydrographic Atlas of the World Ocean Circulation Experiment (WOCE). Volume 1: Southern Ocean, edited by: Sparrow, M., Chapman, P., and Gould, J., International WOCE Project Office, Southampton, U.K., ISBN 0904175-49-9, 2005.

Orsi, A. H., Johnson, G. C., and Bullister, J. L.: Circulation, mixing, and production of antarctic bottom water, Prog. Oceanogr., 43, 55-109, doi:10.1016/S0079-6611(99)00004-X, 1999.

Owens, W. B. and Wong, A. P. S.: An improved calibration method for the drift of the conductivity sensor on autonomous ctd profiling floats by $\theta-$ s climatology, Deep-Sea Res. Pt. I, 56, 450-457, doi:10.1016/j.dsr.2008.09.008, 2009.

Rabe, B., Karcher, M., Schauer, U., Toole, J. M., Krishfield, R. A., Pisarev, S., Kauker, F., Gerdes, R., and Kikuchi, T.: An assessment of arctic ocean freshwater content changes from the 1990s to the 2006-2008 period, Deep-Sea Res. Pt. I, 58, 173185, doi:10.1016/j.dsr.2010.12.002, 2011.

Roemmich, D. and Gilson, J.: The 2004-2008 mean and annual cycle of temperature, salinity, and steric height in the global ocean from the argo program, Prog. Oceanogr., 82, 81-100, doi:10.1016/j.pocean.2009.03.004, 2009.

Schroeder, M. and Fahrbach, E.: On the structure and the transportof the eastern Weddell Gyre, Deep-Sea Res. Pt. II, 46, 501-527, doi:10.1016/S0967-0645(98)00112-X, 1999.

Sterl, A.: On the impact of gap-filling algorithms on variability patterns of reconstracted oceanic surface fields. Geophys. Res. Lett., 28, 2473-2476, 2001.

von Schuckmann, K. and Le Traon, P. Y.: How well can we derive global ocean indicators from argo data?, Ocean Sci., 7, 783-791, doi:10.5194/os-7-783-2011, 2011.

Wong, A., Keeley, R., Carval, T., and the Argo Data Management Team: Argo Quality Control Manual, doi:10.13155/33951, 2014.

Wong, A. P. S., Johnson, G. C., and Owens, W. B.: Delayedmode calibration of autonomous ctd profiling float salinity data by $\theta-$ s climatology, J. Atmos. Ocean. Tech., 20, 308318, doi:10.1175/1520-0426(2003)020<0308:dmcoac >2.0.co;2, 2003.

Zweng, M. M., Reagan, J. R., Antonov, J. I., Locarnini, R. A., Mishonov, A. V., Boyer, T. P., Garcia, H. E., Baranova, O. K., Johnson, D. R., Seidov, D., and Biddle, M. M.: World Ocean Atlas 2013. Vol. 2: Salinity, edited by: Levitus, S., NOAA Atlas NESDIS 74, Silver Spring, MD, USA, 39 pp., 2013. 